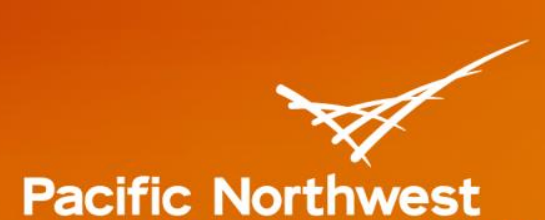

\title{
Summary of Adsorption Capacity and Adsorption Kinetics of Uranium and Other Elements on Amidoxime-based Adsorbents from Time Series Marine Testing at the Pacific Northwest National Laboratory
}

\section{September 2016}

Gary A Gill, Li-Jung Kuo, Jonathan Strivens, Jordana Wood and Nicholas Schlafer, Pacific Northwest National Laboratory, Marine Sciences Laboratory, Sequim, WA 98382

Chris Janke, Sadananda Das, Richard Mayes, Tomonori Saito, Suree Brown and Costas Tsouris, Oak Ridge National Laboratory, Oak Ridge, TN 37831

Chien M. Wai, University of Idaho, Moscow, Idaho 83844 and LCW Supercritical Technologies, Seattle, WA 98103

Horng-Bin Pan, University of Idaho, Moscow, Idaho 83844 


\title{
DISCLAIMER
}

This report was prepared as an account of work sponsored by an agency of the United States Government. Neither the United States Government nor any agency thereof, nor Battelle Memorial Institute, nor any of their employees, makes any warranty, express or implied, or assumes any legal liability or responsibility for the accuracy, completeness, or usefulness of any information, apparatus, product, or process disclosed, or represents that its use would not infringe privately owned rights. Reference herein to any specific commercial product, process, or service by trade name, trademark, manufacturer, or otherwise does not necessarily constitute or imply its endorsement, recommendation, or favoring by the United States Government or any agency thereof, or Battelle Memorial Institute. The views and opinions of authors expressed herein do not necessarily state or reflect those of the United States Government or any agency thereof.

\author{
PACIFIC NORTHWEST NATIONAL LABORATORY \\ operated by \\ BATTELLE \\ for the \\ UNITED STATES DEPARTMENT OF ENERGY \\ under Contract DE-AC05-76RL01830 \\ Printed in the United States of America \\ Available to DOE and DOE contractors from the \\ Office of Scientific and Technical Information, \\ P.O. Box 62, Oak Ridge, TN 37831-0062; \\ ph: (865) 576-8401 \\ fax: $(865) 576-5728$ \\ email: reports@adonis.osti.gov \\ Available to the public from the National Technical Information Service \\ 5301 Shawnee Rd., Alexandria, VA 22312 \\ ph: (800) 553-NTIS (6847) \\ email: orders@ntis.gov <http://www.ntis.gov/about/form.aspx > \\ Online ordering: http://www.ntis.gov
}




\section{Summary of Adsorption Capacity and Adsorption Kinetics of Uranium and Other Elements on Amidoxime-based Adsorbents from Time Series Marine Testing at the Pacific Northwest National Laboratory}

Prepared for: U. S. Department of Energy, Office of Nuclear Energy, Fuel Cycle Research and Development Program, Fuel Resources Program

Prepared by: Gary A Gill, Li-Jung Kuo, Jonathan Strivens, Jordana Wood and Nicholas Schlafer, Pacific Northwest National Laboratory, Marine Sciences Laboratory Sequim, WA 98382

Costas Tsouris, Oak Ridge National Laboratory, Oak Ridge, TN 37831

Chien M. Wai, University of Idaho, Moscow, Idaho 83844 and LCW

Supercritical Technologies, Seattle, WA 98103

Horng-Bin Pan, University of Idaho, Moscow, Idaho 83844

Milestone Number: M3FT-16PN030201044

Work Package Number: FT-16PN03020104

Milestone Due Date: September 1, 2016

U. S. DOE-NE Program Manager: Dr. Stephen Kung

Milestone Level: M3

PNNL Information Release Number: PNNL-25899

Prepared for the U.S. Department of Energy under Contract

DE-AC05-76RL01830. Pacific Northwest National Laboratory, Richland, Washington 99352 


\section{Executive Summary}

The Pacific Northwest National Laboratory (PNNL) has been conducting marine testing of uranium adsorbent materials for the Fuel Resources Program, Department of Energy, Office of Nuclear Energy (DOE-NE) beginning in FY 2012. The marine testing program is being conducted at PNNL's Marine Sciences Laboratory (MSL), located at Sequim Bay, along the coast of Washington. One of the main efforts of the marine testing program is the determination of adsorption capacity and adsorption kinetics for uranium and selected other elements (e.g. vanadium, iron, copper, nickel, and zinc) for adsorbent materials provided primarily by Oak Ridge National Laboratory (ORNL), but also includes other Fuel Resources Program participants. This report summarizes the major marine testing results that have been obtained to date using time series sampling for 42 to 56 days using either flow-through column or recirculating flume exposures. The major results are highlighted in this report and the full data sets are appended as a series of Excel spreadsheet files.

Over the four year period (2012-2016) that marine testing of amidoxime-based polymeric adsorbents was conducted at PNNL's Marine Science Laboratory, there has been a steady progression of improvement in the 56-day adsorbent capacity from $3.30 \mathrm{~g} \mathrm{U} / \mathrm{kg}$ adsorbent for the ORNL $38 \mathrm{H}$ adsorbent to the current best performing adsorbent prepared by a collaboration between the University of Tennessee and ORNL to produce the adsorbent SB12-8, which has an adsorption capacity of $6.56 \mathrm{~g} \mathrm{U} / \mathrm{kg}$ adsorbent. This nearly doubling of the adsorption capacity in four years is a significant advancement in amidoxime-based adsorbent technology and a significant achievement for the Uranium from Seawater program. The achievements are evident when compared to the several decades of work conducted by the Japanese scientists beginning in the 1980's (Kim et al., 2013). The best adsorbent capacity reported by the Japanese scientists was $3.2 \mathrm{~g} \mathrm{U} / \mathrm{kg}$ adsorbent for a 180 day deployment at temperatures between 15 and $25{ }^{\circ} \mathrm{C}$ (Kim et al., 2013) The majority of the capacities the Japanese scientists reported were less than $2 \mathrm{~g}$ $\mathrm{U} / \mathrm{kg}$ adsorbent (Kim et al., 2013).

Repeated time series measurements of a common formulation of amidoxime-based adsorbent, the ORNL AF series, by both flow-through column (3.91 $\pm 0.11 \mathrm{~g} \mathrm{U} / \mathrm{kg}$ adsorbent). and recirculating flume exposures $(4.03 \pm 0.12 \mathrm{~g} \mathrm{U} / \mathrm{kg}$ adsorbent $)$ produced 56-day adsorption capacities that agreed extremely well. This excellent agreement generates confidence that the testing procedures are accurate and reliable and moreover, that the technology to produce the adsorbents is highly reliable and reproducible, lending additional confidence of the robustness and homogeneity of the production technology. 
PNNL-25899

\section{Acronyms and Abbreviations}

$\begin{array}{ll}\text { ATRP } & \text { Atom-Transfer Radical Polymerization } \\ \text { DOE } & \text { U.S. Department of Energy } \\ \text { DOE-NE } & \text { U.S. Department of Energy, Office of Nuclear Energy } \\ \text { ICP-MS } & \text { Inductively Coupled Plasma Mass Spectrometry } \\ \text { ICP-OES } & \text { Inductively Coupled Plasma Optical Emission Spectrometry } \\ \text { LCW } & \text { LCW Supercritical Technologies, LLC } \\ \text { MSL } & \text { Marine Sciences Laboratory } \\ \text { NIST } & \text { National Institute of Standards and Technology } \\ \text { ORNL } & \text { Oak Ridge National Laboratory } \\ \text { OSLSM } & \text { One-Site Ligand Saturation Modeling } \\ \text { PNNL } & \text { Pacific Northwest National Laboratory } \\ \text { RIGP } & \text { Radiation Induced Graft Polymerization } \\ \text { UT } & \text { University of Tennessee }\end{array}$


PNNL-25899

\section{Contents}

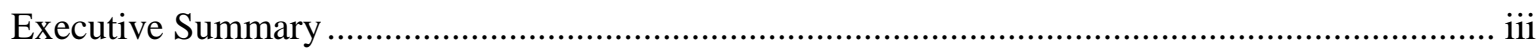

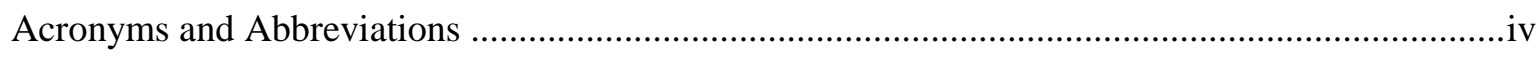

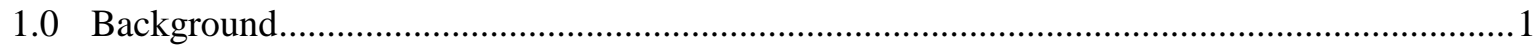

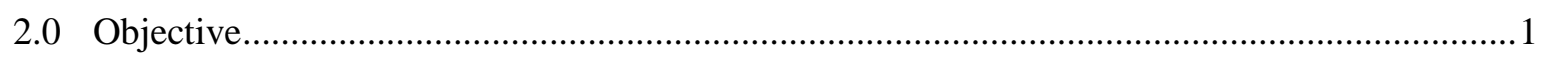

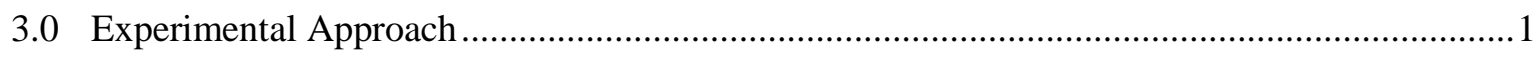

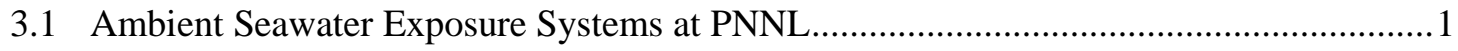

3.1.1 Exposures With Flow-through Cartridge Filters ...............................................

3.1.2 Flow-through Column Exposure System ....................................................... 2

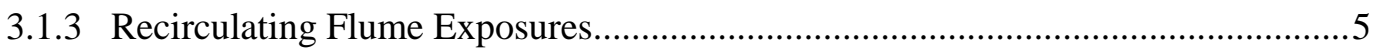

3.2 Water Quality, Temperature and Flow-rate Monitoring …..........................................

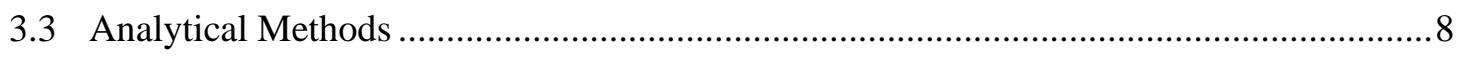

3.3.1 Determination of Uranium and Trace Elements on Adsorbent Materials ...............8

3.3.2 Determination of Uranium and Other Elements in Seawater .................................8

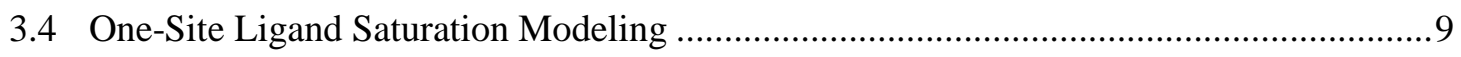

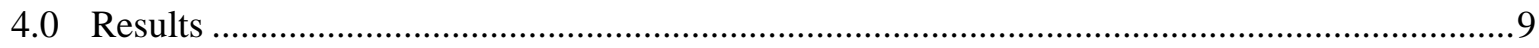

4.1 Flow-Through Column Exposures ……............................................................. 10

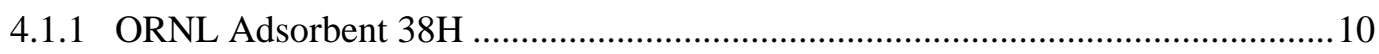

4.1.2 ORNL AF Series Adsorbents ......................................................................... 11

4.1.3 ORNL AI Series Adsorbents ....................................................................... 13

4.1.4 New Formulations of Amidoxime-based Adsorbents from ORNL .......................15

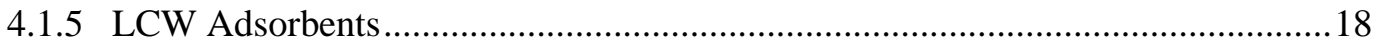

4.1.6 University of Tennessee/ORNL SB Series Adsorbents .....................................21

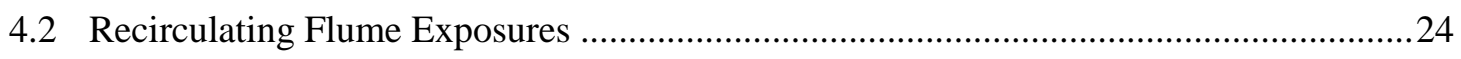

4.2.1 Effect of Flow-rate on Adsorption Capacity .....................................................24

4.2.2 Initial Procedural Development Tests with the ORNL AF1B17-2 Adsorbent......25

4.2.3 Replicate AF1 Braid Exposure Tests ...............................................................2

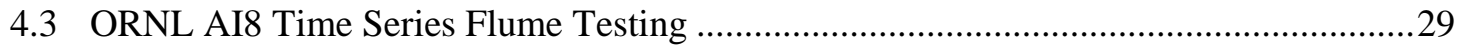

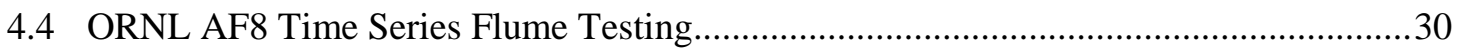

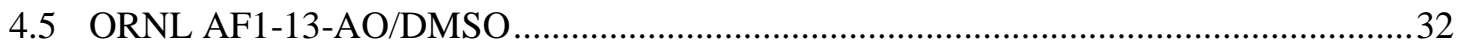

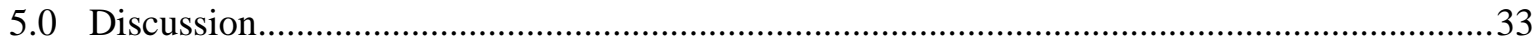

5.1 Summary of and Comparison of Flow-Through Column and Recirculating Flume Time

Series Exposure Tests........................................................................................... 33

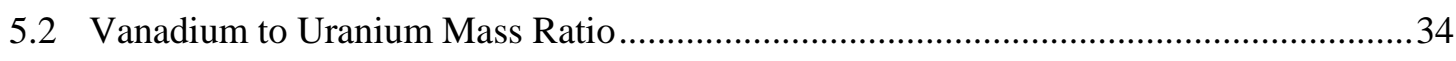

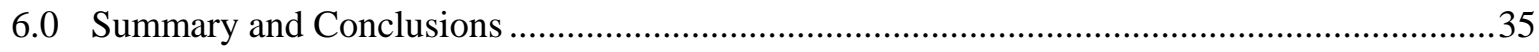

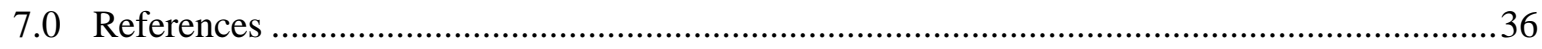


PNNL-25899

\section{Figures}

Figure 1. Flow-through cartridge system used for time series testing of the ORNL adsorbent $38 \mathrm{H}$

Figure 2. Layout and components of the seawater delivery and multi-port manifold system used for exposing uranium adsorbent materials in flow-through columns to filtered ambient seawater under controlled temperature and flow conditions.

Figure 3. Two, 24 port manifold systems (back to back) with flow-through columns attached........4

Figure 4. Nominal one inch ID (2.28 cm actual diameter) flow-through columns packed with

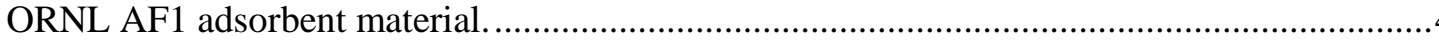

Figure 5. Side view depiction of the recirculating flume system used for exposing braided adsorbent material to filtered or unfiltered natural seawater under controlled temperature and flow-rate (linear velocity) conditions. Six braided adsorbent materials are depicted within the flume. An external pump is used to recirculate seawater in the flume. The linear velocity in the flume is controlled by a gate valve on exit of the pump. Fresh seawater is fed into the flume using the seawater delivery system depicted in Figure 2. Seawater rises in the flume to the height of the overflow tube and then spills out at the same rate as it is introduced from the head tank.

Figure 6. Flumes used for studying the effect of linear velocity on adsorption performance. The flume on the left is the $8 \mathrm{ft}$. flume (Flume B) and the flume on the right is the $6 \mathrm{ft}$. flume (Flume $\mathrm{C}$ ) that is described in Table 2. The recirculation pump for flume $\mathrm{C}$ is shown in the lower left side of the picture. The inlet for fresh seawater is introduced through the $1 / 2 \mathrm{inch}$ poly tubing on the near side of the flumes....

Figure 7. Adsorbent braid attached to a short length of 1/4-inch diameter polyethylene tubing. The tubing end is inserted into a PVC block attached to the bottom of the flume, fixing the braid in the flume in the desired exposure position.

Figure 8. Time Series determinations of adsorption capacity determined for the ORNL adsorbent $38 \mathrm{H}$. All data were normalized to a salinity of 35

Figure 9. Time Series measurements of adsorption capacity for five separate experiments with the ORNL adsorbent AF1 at $20^{\circ} \mathrm{C}$ using filtered Sequim Bay seawater and flow-through column exposure. The best fit line drawn through the data points was determined using onesite ligand saturation modelling. All data were normalized to a salinity of 35 .

Figure 10. Time Series measurements of adsorption capacity for the ORNL adsorbent AF1FR2 at $20{ }^{\circ} \mathrm{C}$ using filtered Sequim Bay seawater and a flow-through column exposure. The best fit line drawn through the data points was determined using one-site ligand saturation modelling. All data were normalized to a salinity of 35 .

Figure 11. Time Series measurements of adsorption capacity for the ORNL adsorbent AI8 at 20 ${ }^{\circ} \mathrm{C}$ using filtered Sequim Bay seawater and a flow-through column exposure. The best fit line drawn through the data points was determined using one-site ligand saturation modelling. All data were normalized to a salinity of 35 .

Figure 12. Time Series measurements of adsorption capacity for the ORNL adsorbent $\mathrm{AN} / \mathrm{MA} / 42 \mathrm{kGY}$-a1 at $20{ }^{\circ} \mathrm{C}$ using filtered Sequim Bay seawater and a flow-through column exposure. The best fit line drawn through the data points was determined using one-site ligand saturation modelling. All data were normalized to a salinity of 35 . 
Figure 13. Time Series measurements of adsorption capacity for the ORNL adsorbent MAN1$\mathrm{AO} / \mathrm{DMSO}$ at $20^{\circ} \mathrm{C}$ using filtered Sequim Bay seawater and a flow-through column exposure. The best fit line drawn through the data points was determined using one-site ligand saturation modelling. All data were normalized to a salinity of 35 .

Figure 14. Time Series measurements of adsorption capacity for the ORNL adsorbent MAN8$\mathrm{AO} / \mathrm{DMSO}$ at $20^{\circ} \mathrm{C}$ using filtered Sequim Bay seawater and a flow-through column exposure. The best fit line drawn through the data points was determined using one-site ligand saturation modelling. All data were normalized to a salinity of 35 .

Figure 15. Time series measurements of adsorption capacity for uranium and selected trace elements with the LCW adsorbent LCW-2 at $20{ }^{\circ} \mathrm{C}$ using a flow-through column exposure with filtered Sequim Bay seawater. The best fit line drawn through the data points was determined using one-site ligand saturation modelling. All data were normalized to a salinity of 35 .

Figure 16. Time series measurements of adsorption capacity for uranium and selected trace elements with the LCW adsorbent LCW-MSL-10 at $20^{\circ} \mathrm{C}$ using a flow-through column exposure with filtered Sequim Bay seawater. The best fit lines drawn through the data points were determined using one-site ligand saturation modelling. All data were normalized to a salinity of 35

Figure 17. Time Series measurements of adsorption capacity for the UT/ORNL adsorbent SB11295 at $20{ }^{\circ} \mathrm{C}$ using filtered Sequim Bay seawater and a flow-through column exposure. The best fit line drawn through the data points was determined using one-site ligand saturation modelling. All data were normalized to a salinity of 35

Figure 18. Time Series measurements of adsorption capacity for the UT/ORNL adsorbent SB128 at $20^{\circ} \mathrm{C}$ using filtered Sequim Bay seawater and a flow-through column exposure. The best fit line drawn through the data points was determined using one-site ligand saturation modelling. All data were normalized to a salinity of 35 .

Figure 19. Comparison of time series measurements of adsorption capacity for the UT/ORNL adsorbents SB11-295 and SB12-8 at $20^{\circ} \mathrm{C}$ using filtered Sequim Bay seawater and a flowthrough column exposure. The best fit line drawn through the data points was determined using one-site ligand saturation modelling. All data were normalized to a salinity of $35 \ldots . . .24$

Figure 20. Time series measurements of adsorption capacity of the ORNL adsorbent AF1B17-2 using a recirculating flume exposure with natural filtered seawater.......................................25

Figure 21. Uranium concentrations in the seawater entering the flume and within the flume during the first flume exposure experiment.

Figure 22. Time Series measurements of adsorption capacity for four separate simultaneous deployments in a recirculating flume of the ORNL adsorbent $\mathrm{AF} 1$ at $20{ }^{\circ} \mathrm{C}$ using filtered Sequim Bay seawater. The best fit line drawn through the data points was determined using one-site ligand saturation modelling. All data were normalized to a salinity of 35 .

Figure 23. Time Series measurements of adsorption capacity for three separate simultaneous deployments in a recirculating flume of the ORNL adsorbent $\mathrm{AF} 1$ at $20^{\circ} \mathrm{C}$ using filtered Sequim Bay seawater. The best fit line drawn through the data points was determined using one-site ligand saturation modelling. All data were normalized to a salinity of 35 .

Figure 24. Time series measurements of adsorption capacity for all seven deployments of the ORNL adsorbent AF1 at $20^{\circ} \mathrm{C}$ using filtered Sequim Bay seawater. The best fit line drawn through the data points was determined using one-site ligand saturation modelling. All data

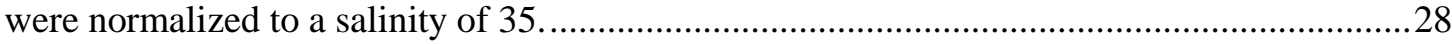


Figure 25. Time series measurements of adsorption capacity for the ORNL adsorbent A18 at 20 ${ }^{\circ} \mathrm{C}$ using filtered Sequim Bay seawater. The best fit line drawn through the data points was determined using one-site ligand saturation modelling. All data were normalized to a salinity of 35 .

Figure 26. Time series measurements of adsorption capacity for the ORNL adsorbent AF8 at 20 ${ }^{\circ} \mathrm{C}$ using filtered Sequim Bay seawater. The best fit line drawn through the data points was determined using one-site ligand saturation modelling. All data were normalized to a salinity of 35 .

Figure 27. Time series measurements of adsorption capacity for the ORNL adsorbent AF1-13$\mathrm{AO} / \mathrm{DMSO}$ at $20^{\circ} \mathrm{C}$ using filtered Sequim Bay seawater. The best fit line drawn through the data points was determined using one-site ligand saturation modelling. All data were normalized to a salinity of 35 . . .

\section{Tables}

Table 1. One-site ligand saturation modelling of uranium adsorption on the ORNL adsorbent $38 \mathrm{H}$

Table 2. One-Site ligand saturation modelling of the AF1 adsorbent for five separate determinations using flow-through column exposures.

Table 3. One-Site ligand saturation modelling of 56-day time series measurements with the ORNL AF1FR2 adsorbent using a flow-through column exposure.

Table 4. One-Site ligand saturation modelling of 56-day time series measurements with the ORNL AI8 adsorbent using a flow-through column exposure.

Table 5. One-site ligand saturation modelling of 56-day time series adsorption capacity measurements with the ORNL AN/MA/42kGY-a1 adsorbent using a flow-through column exposure with filtered Sequim Bay seawater.

Table 6. One-site ligand saturation modelling of 56-day time series adsorption capacity measurements with the ORNL MAN1-AO/DMSO adsorbent using a flow-through column exposure with filtered Sequim Bay seawater.

Table 7. One-site ligand saturation modelling of 56-day time series adsorption capacity measurements with the ORNL MAN8-AO/DMSO adsorbent using a flow-through column exposure with filtered Sequim Bay seawater.

Table 8. One-site ligand saturation modelling of the 56-day time series data for uranium and selected trace elements for the adsorbent LCW-2.

Table 9. One-site ligand saturation modelling of the 70-day time series data for uranium and selected trace elements for the adsorbent LCW-MSL-10.

Table 10. One-Site ligand saturation modelling of two adsorbent materials prepared by atomtransfer radical polymerization using flow-through column exposures

Table 11. One-site ligand saturation modelling of the experimental data depicted in Figure 5 for the ORNL adsorbent AF1B17-2 exposed to natural seawater in a recirculating flume.

Table 12. One-site ligand saturation modelling for seven separate determinations of the AF1 adsorbent using recirculating flume exposures. 
PNNL-25899

Table 13. One-site ligand saturation modelling for the ORNL adsorbent AI8 using a recirculating flume exposure

Table 14. One-site ligand saturation modelling for ORNL adsorbent AF8 using recirculating

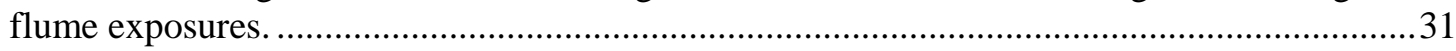

Table 15. One-site ligand saturation modelling for the ORNL adsorbent AF1-13-AO/DMSO

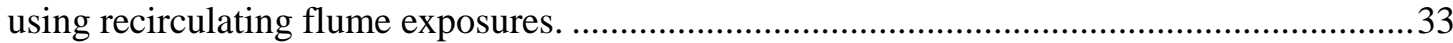

Table 16. Summary of flow-through column testing with amidoxime-based polymeric adsorbents

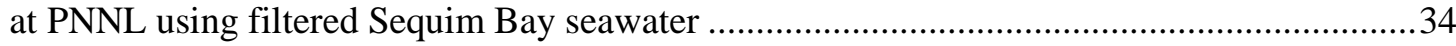

Table 17. Summary of recirculating flume testing with amidoxime-based polymeric adsorbents at

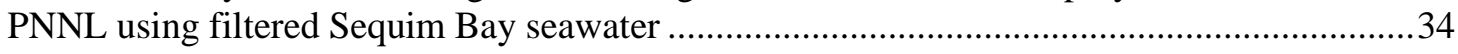

Table 18. Vanadium to uranium mass ratio for several amidoxime-based adsorbents that were exposed to natural seawater in the flow-through column testing at PNNL. .............................35 


\subsection{Background}

The Fuel Resources Program at the U.S. Department of Energy's (DOE), Office of Nuclear Energy (DOE-NE) is developing adsorbent technology to extract uranium from seawater. This technology is being developed to provide a sustainable and economically viable supply of uranium fuel for nuclear reactors (DOE, 2010). A major effort for this program is determination of the adsorbent capacity and saturation kinetics of the adsorbent materials developed by program participants for uranium and selected other elements (e.g. vanadium, iron, copper, nickel, and zinc) using natural seawater under realistic conditions. This marine testing program is being conducted at the Pacific Northwest National Laboratories (PNNL), Marine Sciences Laboratory (MSL) in Sequim, Washington using ambient seawater from Sequim Bay.

Marine testing began at MSL in 2012 and has continued through 2016 as this report is being prepared. Additional testing is scheduled for FY 2017. Details on the marine testing program and a summary of the testing results to date have been reported in the peer-reviewed literature (Gill et al., 2016, Kuo et al, 2016; Park et al., 2016). This report describes the marine testing of amidoxime-based adsorbent materials conducted at PNNL's Marine Sciences Laboratory in Sequim, WA. Additional marine testing was also conducted at the University of Miami's Broad Key Island (BKI) research station using ambient seawater from the coast of Florida. The BKI marine testing is covered in a separate milestone report (Gill et al., 2016) and will not be discussed here.

\subsection{Objective}

This report summarizes the time series measurements of adsorption capacity and adsorption kinetics of amidoxime-based adsorbents for uranium and a suite of other elements determined in natural ambient seawater at the Marine Sciences Laboratory in Sequim, WA.

\subsection{Experimental Approach}

\subsection{Ambient Seawater Exposure Systems at PNNL}

Marine testing was conducted at the MSL, a coastal based marine laboratory within PNNL, using ambient seawater from Sequim Bay, WA. The MSL has a seawater delivery system that can provide ambient seawater into a "wet laboratory" for scientific investigations. Ambient seawater is drawn by pump from a depth of $\sim 10 \mathrm{~m}$ from Sequim Bay through a plastic pipe. Raw seawater is pumped directly into the laboratory for use. Filtered seawater is obtained by first passing raw seawater through an Arkal Spin Klin ${ }^{\mathrm{TM}}$ filter system (nominal pore size $40 \mu \mathrm{m}$ ) 
to remove large particles. The partially filtered seawater is then stored in a large volume ( 3,500 gal) reservoir tank outside the laboratory. This seawater is gravity fed into the laboratory research facilities through PVC piping where it can be passed through additional filtration to remove finer particles if needed at the point of use. Three types of exposure systems were employed in this program: (1) flow-through cartridge filters and (2) flow-through columns for testing of loose fibers and other loose materials; and (3) a recirculating water flume for testing of braided adsorbent material. Additional details about the seawater exposure system at PNNL are given in Gill et al. (2016).

\subsubsection{Exposures With Flow-through Cartridge Filters}

Initial marine testing at PNNL's Marine Sciences Laboratory was conducted by Costas Tsouris of Oak Ridge National Laboratory (ORNL) using all Teflon flow-through filter cartridges that were packed with adsorbent (Figure 1). The cartridges were prepared at ORNL, shipped to MSL, the exposure was conducted, and the cartridges were returned to ORNL for analysis. Seawater was delivered to the cartridges and the flow-rate was controlled using an inline peristaltic pump with a Teflon pump head. Cartridges for a time series were placed in series as shown in Figure 1. The results from this initial testing were reported in Kim et al., (2014).

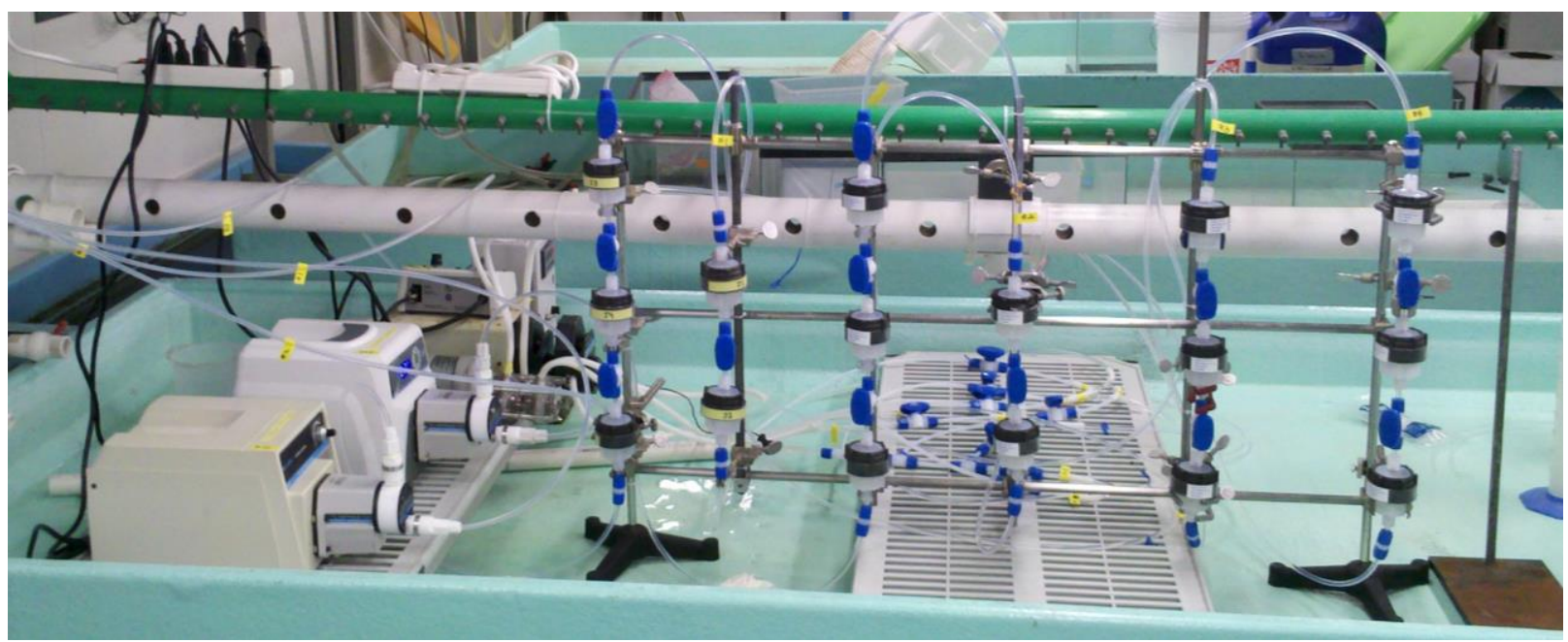

Figure 1. Flow-through cartridge system used for time series testing of the ORNL adsorbent $38 \mathrm{H}$.

\subsubsection{Flow-through Column Exposure System}

Figure 2 shows a diagram of the seawater delivery and manifold system used to expose adsorbent materials to $0.45 \mu \mathrm{m}$ filtered ambient seawater in flow-through columns. Figure 3 is a picture of the manifold with flow-through columns attached. Seawater from a large outside storage reservoir is fed sequentially through $5 \mu \mathrm{m}$ and then $1 \mu \mathrm{m}$ cellulose filters and then collected in a $180 \mathrm{~L}$ fiberglass reservoir tank referred to as a "head tank." Seawater in the head tank is heated to the desired temperature using a $10 \mathrm{~kW}$ all titanium immersion heater. Temperature-controlled $\left(20 \pm 1.5^{\circ} \mathrm{C}\right)$ seawater is drawn from the head tank with a pump (non- 
metallic pump head), passed through a 0.35 to $0.45 \mu \mathrm{m}$ polyethersulfone (Memtrex MP, GE Power and Water) or cellulose membrane cartridge filter and into the 24-port PVC manifold. Seawater continually recirculates through the manifold and is returned to the head tank if it does not get used for flow-through column exposure. Pressure (2-6 psi) in the manifold is controlled with a gate valve at the outlet of the manifold.

MSL has four separate 24-port manifolds, linked to three separate head tanks, permitting testing of 96 adsorbent materials in flow-through columns simultaneously. The flow-rate of seawater passing through the columns is grossly controlled by varying the seawater delivery pressure in the manifold and then fine scale flow adjustments using a needle valve placed on the outlet of each flow-through column. A turbine flow sensor (DFS-2W, Clark Solutions) is attached to the outlet tubing to monitor and record the flow through each column. The signals from the sensors are captured by a homemade instrument package operated with National Instruments LabView software, which displays in real time the flow-rate of each column on the manifold and records integrated flow-rate measurements in increments ranging from a few seconds to several hours.

The temperature of the seawater flowing through the exposure system was monitored and recorded at the outlet of columns using an Omega model RDXL4SD handheld meter equipped with a long lead and non-metallic temperature probe. The temperature was recorded every 5-10 minutes by attaching the meter to a laptop computer using data recording and storage software provided with the instrument.

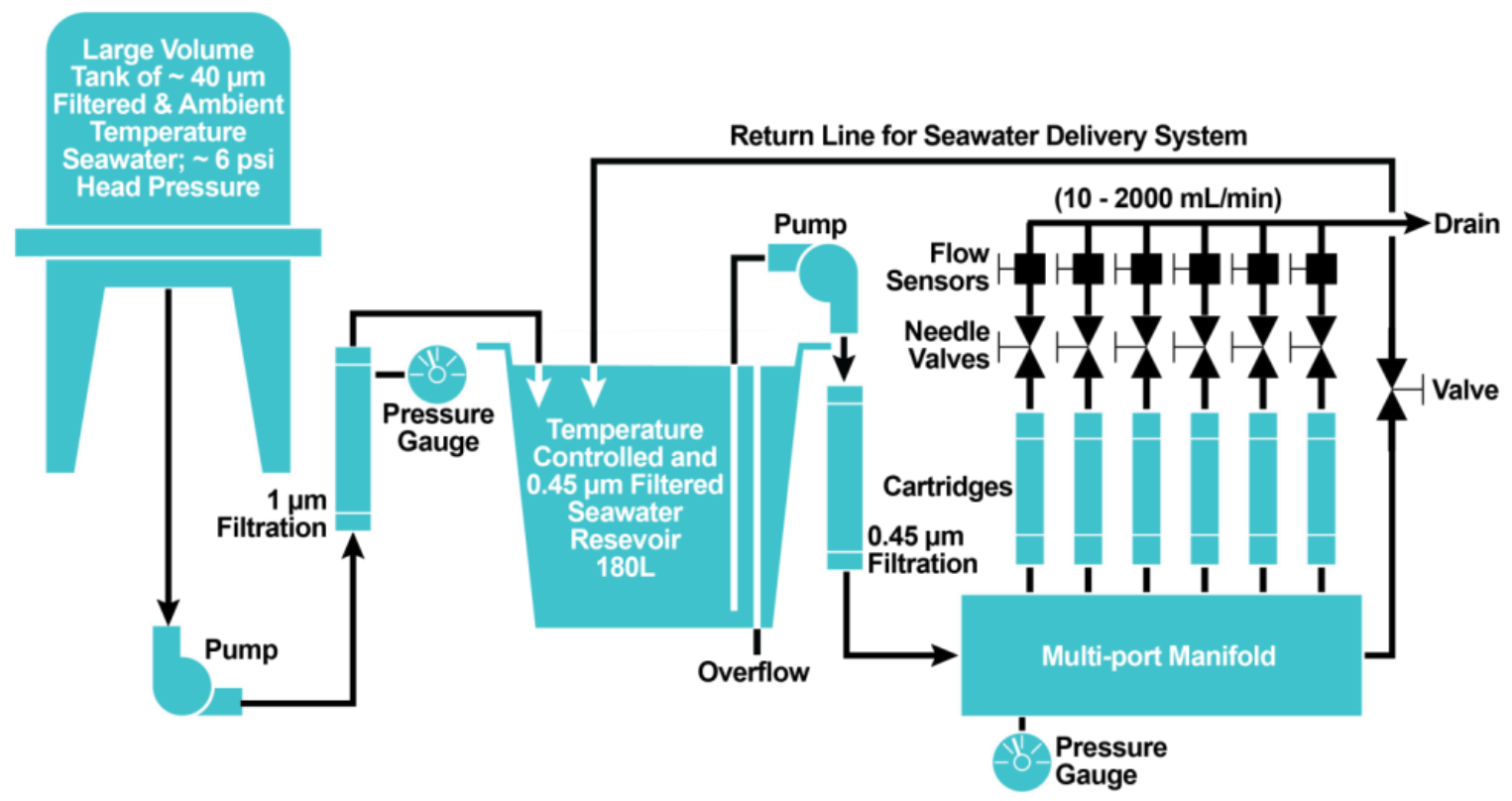

Figure 2. Layout and components of the seawater delivery and multi-port manifold system used for exposing uranium adsorbent materials in flow-through columns to filtered ambient seawater under controlled temperature and flow conditions. 


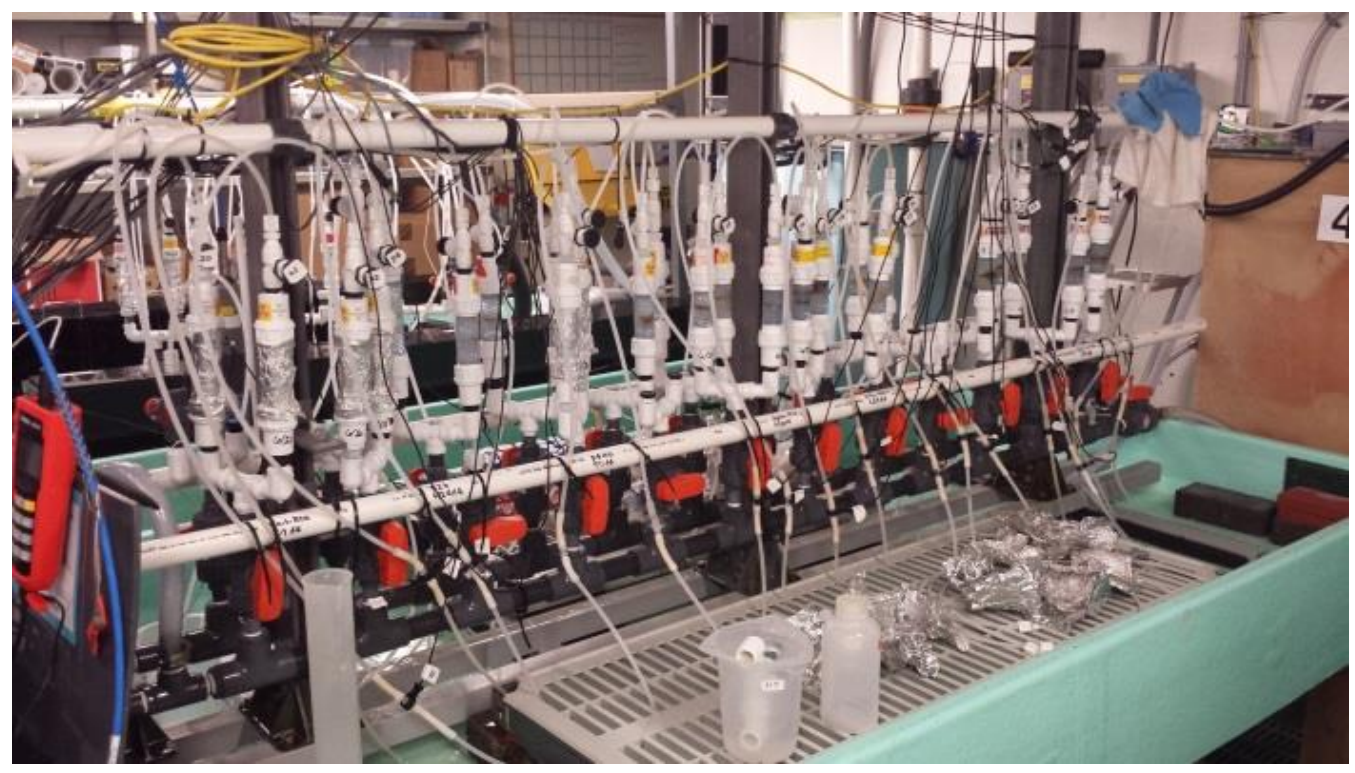

Figure 3. Two, 24 port manifold systems (back to back) with flow-through columns attached.

The PNNL flow-through columns are constructed from all plastic components using commercially available materials. An example of a nominal 1 -inch $(2.28 \mathrm{~cm}$ actual $)$ diameter column is shown in Figure 4. The column consists of a clear PVC tubing (Harvel Clear ${ }^{\text {TM }}$ Rigid PVC Pipe) with threaded ends. Threaded PVC pipe fittings are used as end caps. Porous polyethylene sheets (Bel-Art Fritware ${ }^{\circledR}$ ) with pore diameter of $\sim 110 \mu \mathrm{m}$ are used to construct frits. The frits are fitted inside the end caps and serve to contain the column contents. O-rings are placed on both sides of the frit and seal the end cap to the end of the column. Five mm diameter glass beads were used as column packing material to contain the adsorbent material.

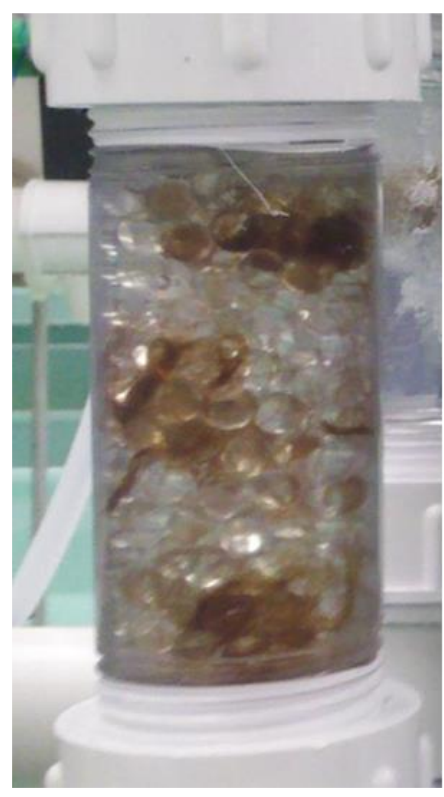

Figure 4. Nominal one inch ID (2.28 cm actual diameter) flow-through columns packed with ORNL AF1 adsorbent material. 
PNNL-25899

\subsubsection{Recirculating Flume Exposures}

The Pacific Northwest National Laboratory has developed flow-through channels for conducting flume experiments under controlled temperature and flow-rate conditions. Different size pumps and flume dimensions are used to create a range in flow-rate (linear velocity). The flumes were constructed with different dimensions and recirculating pump sizes for conducting exposure tests with braided adsorbent material under controlled temperature and flow-rate (linear velocity) conditions. The target linear velocity around which the flows were varied was $2 \mathrm{~cm} / \mathrm{sec}$, which is approximately the linear velocity being used for testing with flow-through columns at PNNL. The flumes were constructed of darkened acrylic material to limit biological growth. Shown in Figure 5 is a cross sectional view of the flume design illustrating the recirculation system and seawater inlet. A picture of the two flumes is shown in Figure 6. Fresh seawater is fed into the flume at flow-rates up to $5 \mathrm{~L} / \mathrm{min}$ using the seawater manifold delivery system depicted in Figure 2. A tubing line was run from one or more of the manifold ports directly into the flume to achieve the desired seawater delivery rates. The rate of fresh seawater delivery was controlled using a needle valve mounted on one or more ports in the manifold. The height of water in the flume is controlled by the height of the stand pipe, which can be varied between approximately 7 and 11 inches $(18-28 \mathrm{~cm})$. Water within the flume rises until it reaches the height of the standpipe and then spills out of the flume through the standpipe. Raising or lowering the water height changes the cross sectional area of the water in the flume, which in turn is a means to control the linear velocity in the flume.

Braided adsorbents were placed into the flumes for exposure by attaching them to a short length of $1 / 4$ inch polyethylene tubing with cable ties and inserting one end of the tubing into a small block mounted on the bottom of the flume into which a $1 / 4$ inch hole has been drilled (Figure 7). 
PNNL-25899

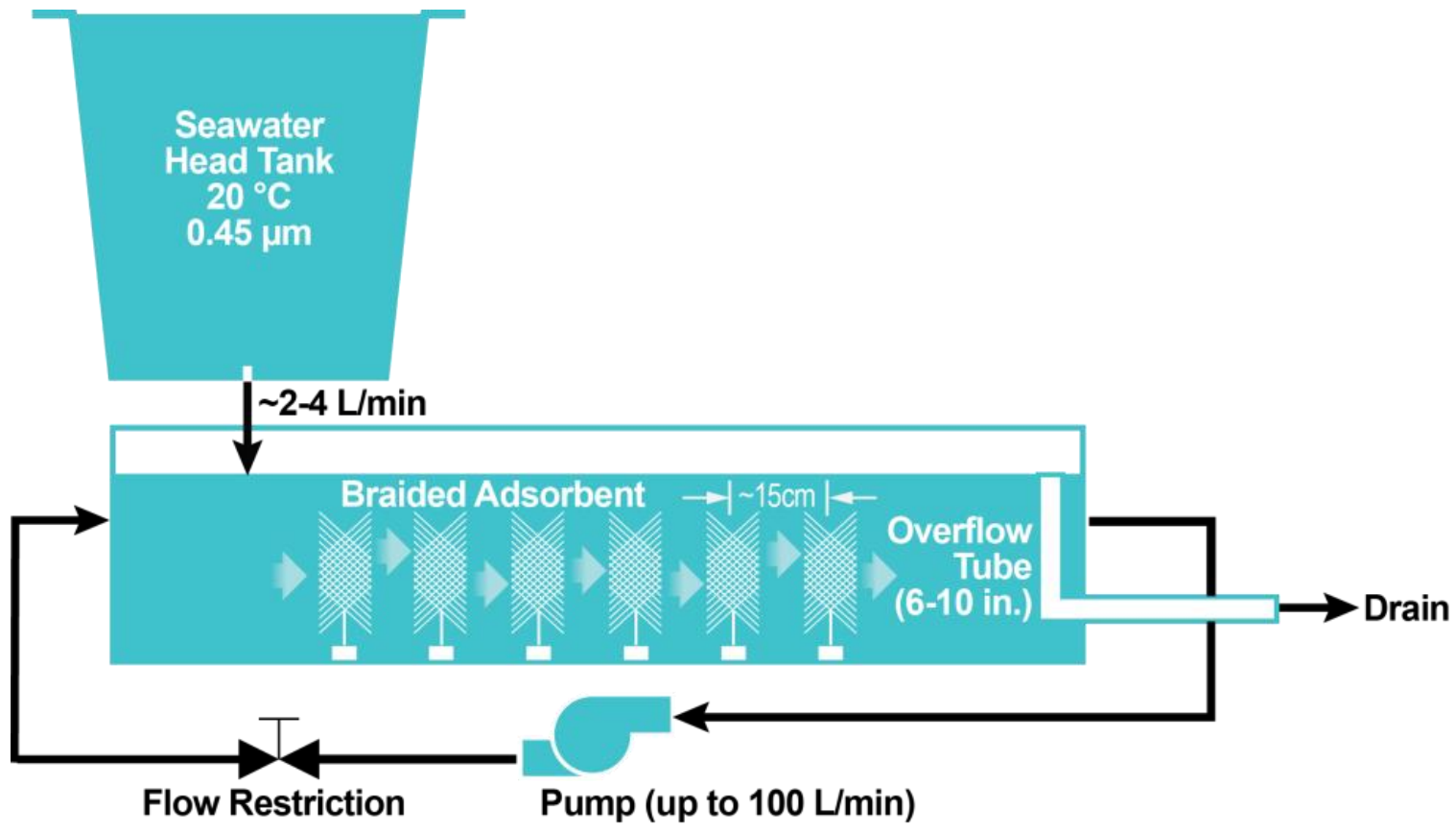

Figure 5. Side view depiction of the recirculating flume system used for exposing braided adsorbent material to filtered or unfiltered natural seawater under controlled temperature and flow-rate (linear velocity) conditions. Six braided adsorbent materials are depicted within the flume. An external pump is used to recirculate seawater in the flume. The linear velocity in the flume is controlled by a gate valve on exit of the pump. Fresh seawater is fed into the flume using the seawater delivery system depicted in Figure 2. Seawater rises in the flume to the height of the overflow tube and then spills out at the same rate as it is introduced from the head tank.

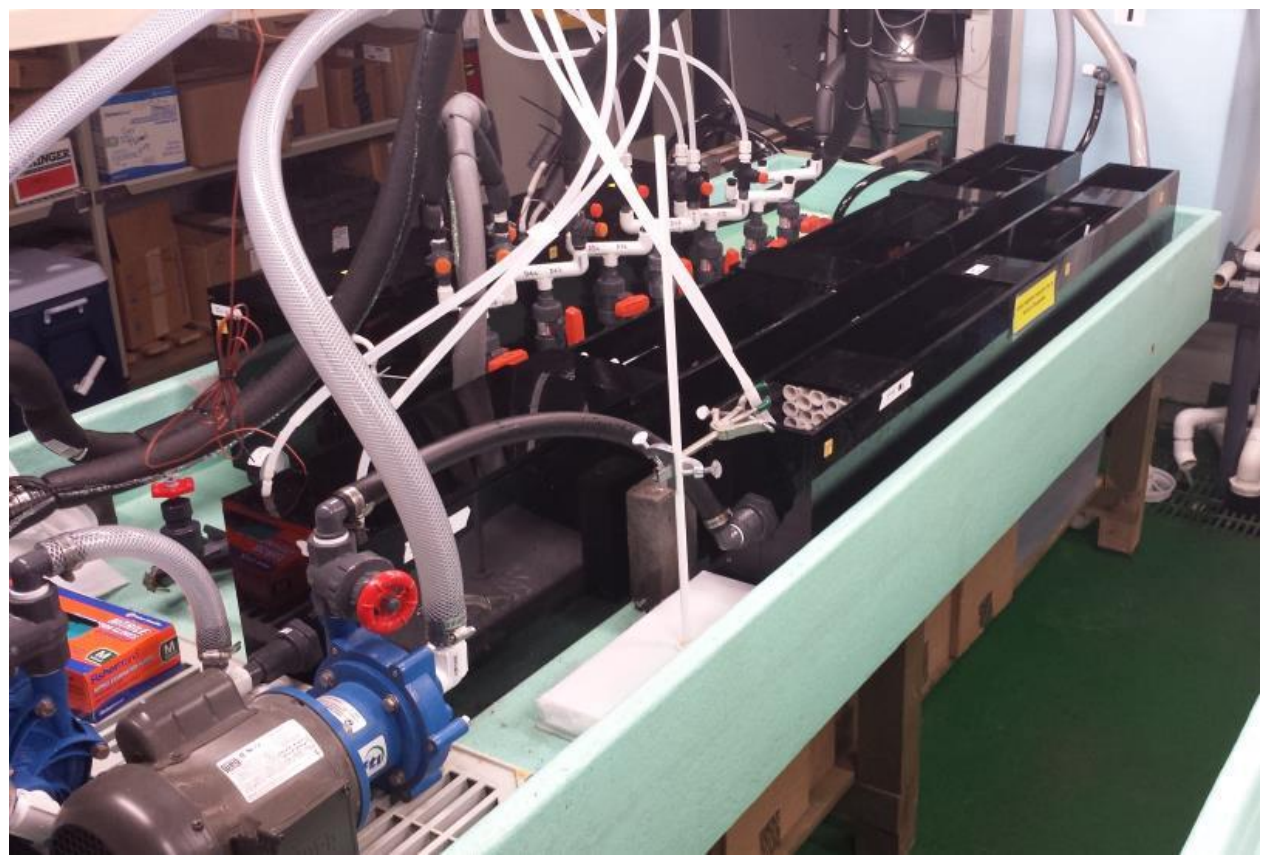

Figure 6. Flumes used for studying the effect of linear velocity on adsorption performance. The flume on the left is the $8 \mathrm{ft}$. flume (Flume B) and the flume on the right is the $6 \mathrm{ft}$. flume (Flume C) that is 
described in Table 2. The recirculation pump for flume $\mathrm{C}$ is shown in the lower left side of the picture. The inlet for fresh seawater is introduced through the $1 / 2$ inch poly tubing on the near side of the flumes

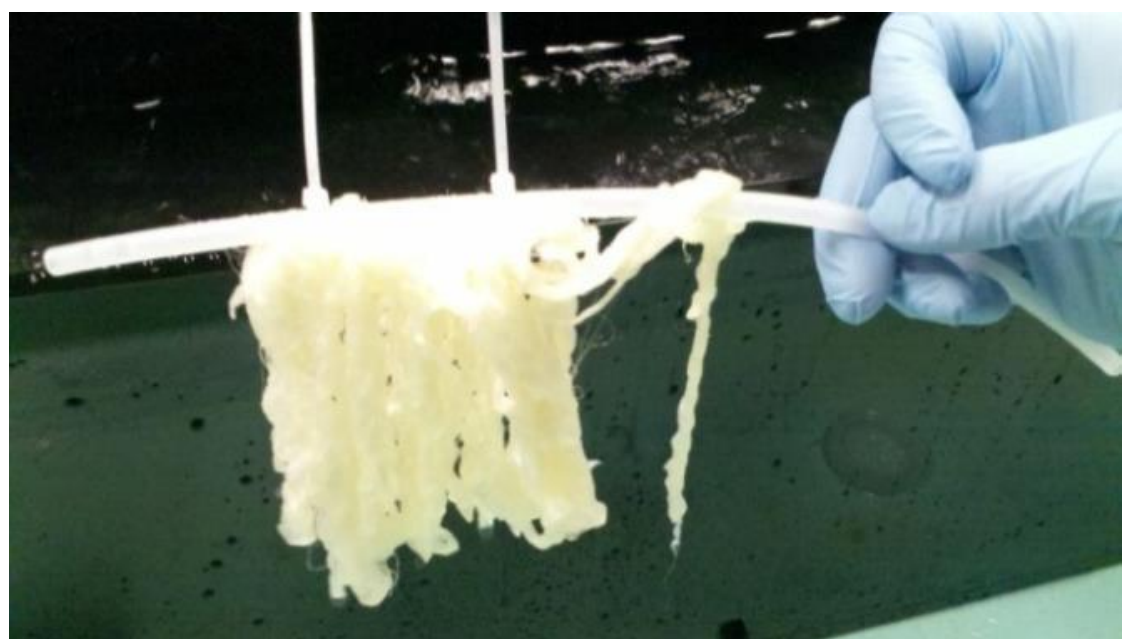

Figure 7. Adsorbent braid attached to a short length of $1 / 4$-inch diameter polyethylene tubing. The tubing end is inserted into a PVC block attached to the bottom of the flume, fixing the braid in the flume in the desired exposure position.

The rate at which fresh seawater is fed into the system and the internal volume of the flume controls the residence time of seawater in the system. For example, with the $6 \mathrm{ft}$. flume, the water residence time is $\sim 20$ minutes. The time to recirculate water is much faster. At a recirculation flow rate of $87 \mathrm{~L} / \mathrm{min}$, the water in the flume is recirculated once every 24 seconds.

\subsection{Water Quality, Temperature and Flow-rate Monitoring}

Salinity and $\mathrm{pH}$ measurements of the seawater exposure system were obtained using handheld probes several times a week during the exposure periods. Salinity was monitored using a YSI model Pro30 and $\mathrm{pH}$ measurements were made using a portable $\mathrm{pH}$ meter (VWR Scientific) equipped with a temperature compensating glass electrode that was calibrated with National Institute of Standards and Technology (NIST) traceable buffers. The $\mathrm{pH}$ and salinity probes were calibrated weekly. High frequency (every 10 minutes) measurements of temperature in the seawater exposure systems were obtained with a thermocouple interfaced to an Omega 4 channel meter and data logger (model HH1384). For the final experiment in 2016 (experiment 4), monitoring of both the seawater exposure systems and the ambient seawater was conducted with in situ YSI probes (model XLM-S in ambient seawater and a retrofitted 600 QS on the flume system) that were equipped with temperature, $\mathrm{pH}$ and conductivity (salinity) probes. Both units had stand-alone data logging capability and data were recorded on an hourly basis during the exposure period to assess how conditions in the exposure system compared with ambient seawater. 
Flow-rate in the flow-through columns was monitored using an in-line turbine-style flow sensor (Model DFS-2W, Digiflow Systems) placed at the outlet of the flow-through columns. Flow-rate in the flumes was monitored using an in-line flow-meter on the recirculation line. The flow-rate in the flume was adjusted by constricting the output from the recirculation pump using a gate valve. The flow-rate was adjusted for both the columns and flume exposures to yield a linear velocity of $2 \mathrm{~cm} / \mathrm{sec}$, consistent with the flows used for seawater exposures at PNNL (Gill et al., 2016).

\subsection{Analytical Methods}

\subsubsection{Determination of Uranium and Trace Elements on Adsorbent Materials}

Analysis of uranium and other elements retained on the adsorbents was conducted at PNNL. Adsorbent materials exposed to seawater were washed with deionized water to remove salts, using a conductivity meter to monitor the salt removal. Samples were then dried at $80^{\circ} \mathrm{C}$ to a constant weight using a heated block (ModBlock ${ }^{\mathrm{TM}}$, CPI International). The dried fibers (50 to $100 \mathrm{mg}$ ) were weighed and then digested with $15 \mathrm{~mL}$ of a high-purity (Trace Metal Grade, Fisher Scientific) 50\% aqua regia acid mixture (3:1; hydrochloric acid: nitric acid) for 3 hours at $85^{\circ} \mathrm{C}$ on a hot block. Analysis of uranium and other trace elements was conducted following dilution of the digestate with $20 \mathrm{~mL}$ of de-ionized water using either a Perkin-Elmer $7300 \mathrm{DV}$ inductively coupled plasma optical emission spectrometer (ICP-OES) or a Thermo Scientific $\mathrm{ICap}^{\mathrm{TM}} \mathrm{Q}$ inductively coupled plasma mass spectrometer (ICP-MS). Quantification with both instruments is based on standard calibration curves.

Analysis of uranium and trace elements on the mini-braid deployments which had biofouling were processed using a variation of the procedure used for braided adsorbents without biofouling. The mini braids were rinsed in deionized water and were then digested without trying to remove the biofouling. After the digestion, the fibers were rinsed to remove acid and were dried and weighed. This weight was then corrected for loss of the amidoxime and co-monomer functional groups mass due to the strong acid digestion. A correction term was determined using a separate set of new fibers (of the formulation deployed) which were conditioned, but were not exposed to seawater, were carried through the digestion process, dried and weighed, and they were then compared to their initial dry weight before the conditioning step. Confirmation of digestion induced weight loss was verified by post-weights of exposed braid snips of the same formulation.

\subsubsection{Determination of Uranium and Other Elements in Seawater}

Determination of uranium and other elements in natural seawater samples was conducted at PNNL's Marine Sciences Laboratory using ICP-MS and either the method of standard addition calibrations or the samples were pre-concentrated onto a chelating ion exchange resin to minimize the seawater matrix, followed by acid elution with quantification against a standard 
calibration curve prepared using on-line pre-concentration (Wood et al., 2016). On-line preconcentration of uranium was conducted using the seaFAST S2 ${ }^{\mathrm{TM}}$ automated sample introduction system (Elemental Scientific) utilizing a seaFAST PFA chelation column packed with iminodiacetic acid chelating ion exchange resin (ESI, Seawater Concentrator Column CF$\mathrm{N}-0200$ ). Analytes were eluted off the column using $10 \% \mathrm{HNO}_{3}$ and detected using a Thermo Elemental ICapQ ICP-MS.

\subsection{One-Site Ligand Saturation Modeling}

Measurements of the adsorption of uranium and other elements from seawater as a function of time onto the adsorbent materials were used to determine the adsorbent capacity and adsorption rate (kinetics) of uranium and other elements. Determination of adsorption capacity and kinetics was conducted using one-site ligand saturation modeling, which was parameterized using the software graphics program SigmaPlot $\odot$. The best-fit line representing the time series adsorption of uranium is given by:

$$
u=\frac{\beta_{\max } t}{K_{d}+t}
$$

Where $u$ is uranium capacity (g U/kg adsorbent), $t$ is exposure time (days), $\beta_{\max }$ is the adsorption capacity at saturation (g U/kg adsorbent), and $K_{d}$ is the half-saturation time (days).

Prior to determination of adsorption capacity and kinetics, the individual capacity determinations were normalized to a salinity of 35 psu using simple proportional relationships. This normalization removes the differences that result from exposures in seawater with varying salinity and hence uranium concentrations. This salinity normalization is also done for the other elements as well, but the normalization is less well defined for non-conservative elements in seawater.

\subsection{Results}

A compilation of all of the uranium and elemental data obtained from the time series measurements of amidoxime-based adsorbent materials presented in this report is provided in a series of Excel spreadsheet files that accompanies this report. All data have been normalized to a salinity of 35 to allow for direct comparison of uranium concentrations at a common salinity. Unless otherwise specified, the temperature of the experiment was conducted at $20^{\circ} \mathrm{C}$, the flowrate (linear velocity) of the seawater through the column or flume was between 2 and $2.5 \mathrm{~cm} / \mathrm{s}$. For the flow-through columns, this corresponded to a flow-rate $>250 \mathrm{~mL} /$ minute using a 1 inch internal diameter column. 
PNNL-25899

\subsection{Flow-Through Column Exposures}

\subsubsection{ORNL Adsorbent 38H}

The first amidoxime-based adsorbent that was tested at PNNL was the ORNL formulation $38 \mathrm{H}$. Preparation of and laboratory testing of this adsorbent has been reported by Kim et al., 2013, 2014 and Oyala et al., 2016. A total of 5 time series experiments were conducted in FY 2012. Four of the experiments were conducted by Dr. Costas Tsouris of Oak Ridge National Laboratory using flow-through column exposures and an independent experiment was conducted by PNNL staff using a flow-through column exposure. The results for the first experiment (ORNL1) are not considered reliable due to problems with maintaining a consistent flow-rate during the experiment. Shown in Figure 8 are the time series data for four of the experiments. The ORNL 2 experiment was conducted using the ORNL cartridges and peristaltic pump system, while the ORNL 3 and PNNL1 experiments were conducted using the PNNL manifold system for seawater exposure. It is important to note that the ORNL experiment 2 was conducted at a temperature of $31.4{ }^{\circ} \mathrm{C}$, while the ORNL 3 and PNNL1 experiments were conducted at $20{ }^{\circ} \mathrm{C}$. At the time these experiments were conducted, the significant impact of temperature on the uranium adsorption capacity of amidoxime-based adsorbents was not known. One-site ligand saturation (OSLS) modelling of the four experiments is given in Table 1.

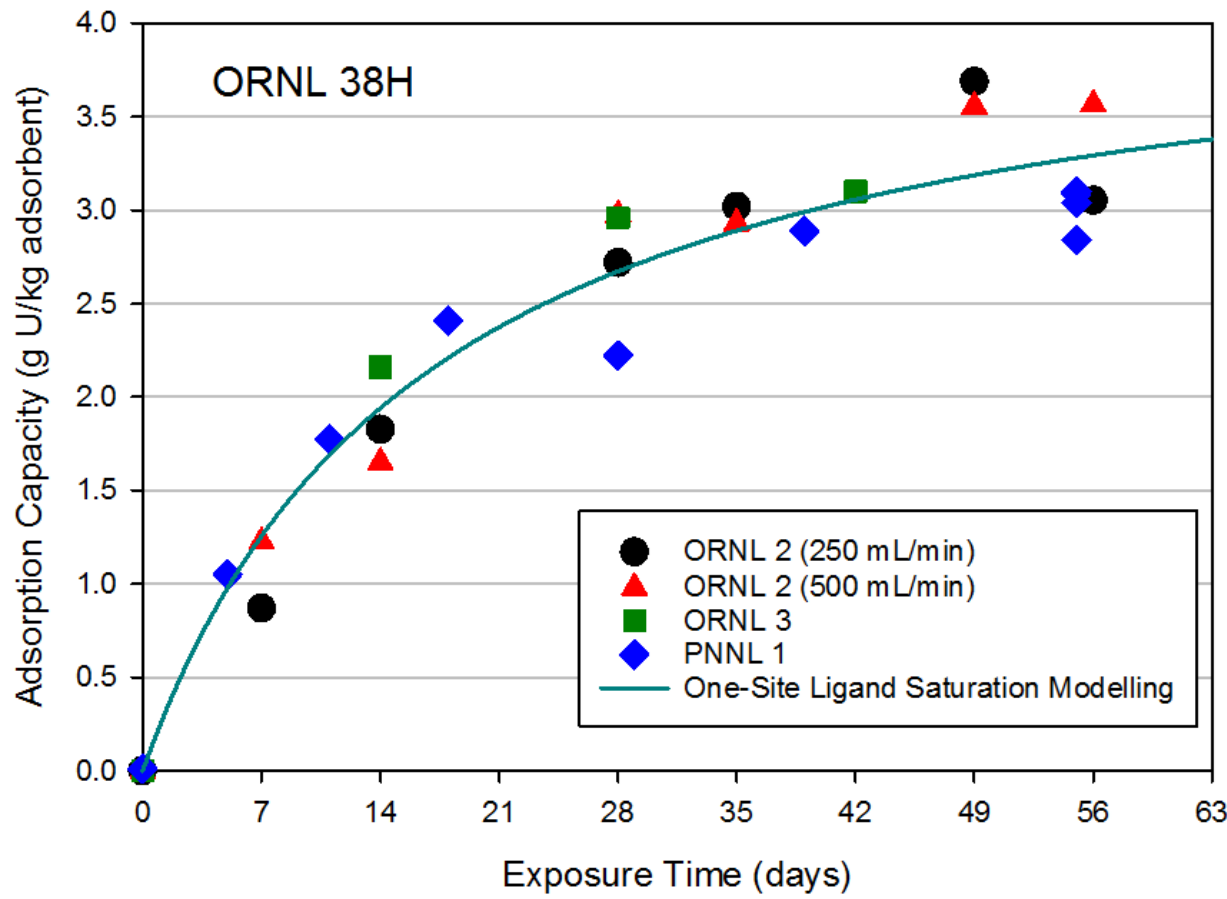

Figure 8. Time Series determinations of adsorption capacity determined for the ORNL adsorbent $38 \mathrm{H}$. All data were normalized to a salinity of 35 . 
PNNL-25899

Table 1. One-site ligand saturation modelling of uranium adsorption on the ORNL adsorbent 38H

\begin{tabular}{ccc}
\hline Modelling Parameter ${ }^{1,2}$ & All Experiments & PNNL1 \\
\hline $\begin{array}{c}\text { Saturation Capacity } \\
\text { (g U/kg adsorbent) }\end{array}$ & $4.29 \pm 0.24$ & $3.65 \pm 0.19$ \\
$\begin{array}{c}\text { 56-day adsorption capacity } \\
\text { (g U/kg adsorbent) }\end{array}$ & $3.30 \pm 0.18$ & $3.01 \pm 0.16$ \\
$\begin{array}{c}\text { Half-saturation time } \\
\text { (days) }\end{array}$ & $16.9 \pm 2.8$ & $11.9 \pm 2.2$ \\
\hline
\end{tabular}

${ }^{1}$ Determined at a temperature of $20^{\circ} \mathrm{C}$

${ }^{2}$ Normalized to a salinity of 35

\subsubsection{ORNL AF Series Adsorbents}

The ORNL AF series of adsorbents are amidoxime-based polymer adsorbents that were synthesized by radiation-induced graft polymerization (RIGP) of acrylonitrile and itaconic acid onto high surface area hollow gear polyethylene fibers. The different AF versions have different degrees of grafting and different monomer/co-monomer mol ratios. In addition, different ratios of solvents (water, methanol, and dimethylsulfoxide) were used for the conversion of the grafted nitrile groups to amidoxime with hydroxylamine. Details of the preparation of the adsorbents are given in Das et al. (2016).

\subsubsection{ORNL AF1 Adsorbent}

There were a total of five separate experiments where time series data were obtained with the ORNL AF1 adsorbent formulation using flow-through column exposures with filtered $(0.45 \mu \mathrm{m})$ Sequim Bay seawater at $20{ }^{\circ} \mathrm{C}$ (Figure 9). One-site ligand saturation modelling combining all the five individual experiments is given in Table 2. The series of experiments in the MSL 3493 series were conducted with both 1 hour and 3 hours of $\mathrm{KOH}$ conditioning time. This experiment revealed that 1 hour of conditioning time resulted in higher adsorption capacities. Therefore, only the one hour conditioning time results are used for this compilation. 
PNNL-25899

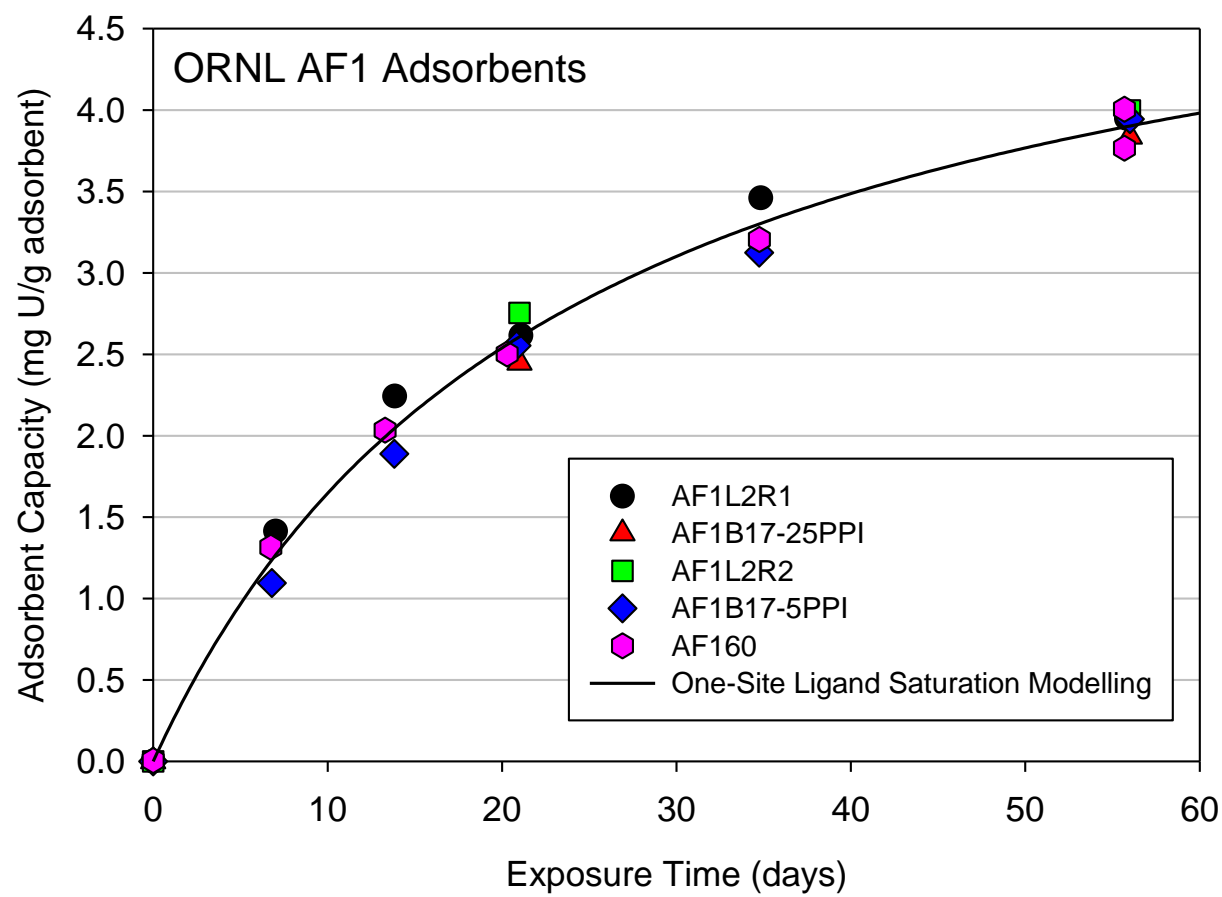

Figure 9. Time Series measurements of adsorption capacity for five separate experiments with the ORNL adsorbent $\mathrm{AF} 1$ at $20^{\circ} \mathrm{C}$ using filtered Sequim Bay seawater and flow-through column exposure. The best fit line drawn through the data points was determined using one-site ligand saturation modelling. All data were normalized to a salinity of 35 .

Table 2. One-Site ligand saturation modelling of the AF1 adsorbent for five separate determinations using flow-through column exposures.

\begin{tabular}{|c|c|c|c|c|}
\hline MSL ID & Adsorbent & $\begin{array}{c}\text { Saturation } \\
\text { Capacity }{ }^{1,2} \\
\text { (g U/kg adsorbent) } \\
\end{array}$ & $\begin{array}{c}\text { 56-day Adsorption } \\
\text { Capacity } 1,2 \\
\text { (g U/kg adsorbent) } \\
\end{array}$ & $\begin{array}{c}\text { Half Saturation } \\
\text { Time } 1,2 \\
\text { (days) } \\
\end{array}$ \\
\hline $3439-1$ & AF1L2R1 & $5.38 \pm 0.20$ & $3.96 \pm 0.21$ & $20 \pm 1.8$ \\
\hline $3439-2^{3}$ & AF1B17-25PPI & 5.82 & 3.83 & 29 \\
\hline $3439-3^{3}$ & AF1L2R2 & 5.48 & 3.99 & 21 \\
\hline $3439-4$ & AF1B17-5PPI & $5.98 \pm 0.26$ & $3.89 \pm 0.17$ & $30 \pm 2.6$ \\
\hline $3437^{4}$ & AF160 & $5.42 \pm 0.22$ & $3.84 \pm 0.16$ & $23 \pm 2.3$ \\
\hline \multicolumn{2}{|c|}{ All Data Combined } & $5.56 \pm 0.15$ & $3.91 \pm 0.11$ & $24 \pm 1.5$ \\
\hline \multicolumn{5}{|c|}{$\begin{array}{l}{ }^{1} \text { Determined at a temperature of } 20^{\circ} \mathrm{C} \\
2^{2} \text { Normalized to a salinity of } 35 \\
{ }^{3} \text { Only two time points, } 21 \text { and } 56 \text { days }\end{array}$} \\
\hline
\end{tabular}

\subsubsection{ORNL AF1FR2 Adsorbent}

Illustrated in Figure 10 are time series measurements for uranium and selected trace elements for the ORNL AF series adsorbent AF1FR2. One-site ligand saturation modelling of the time series data are given in Table 3. 
PNNL-25899

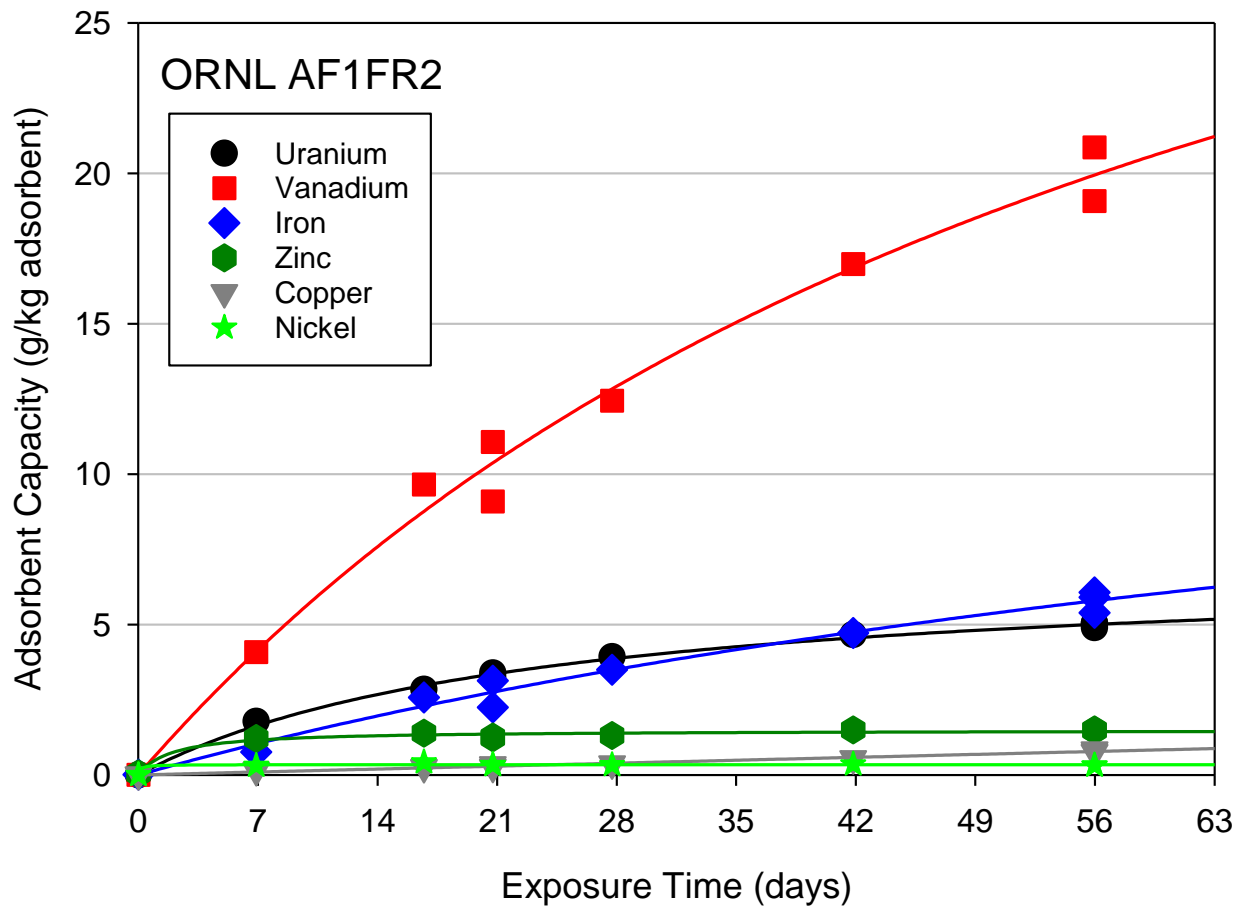

Figure 10. Time Series measurements of adsorption capacity for the ORNL adsorbent AF1FR2 at $20{ }^{\circ} \mathrm{C}$ using filtered Sequim Bay seawater and a flow-through column exposure. The best fit line drawn through the data points was determined using one-site ligand saturation modelling. All data were normalized to a salinity of 35 .

Table 3. One-Site ligand saturation modelling of 56-day time series measurements with the ORNL AF1FR2 adsorbent using a flow-through column exposure.

\begin{tabular}{|c|c|c|c|}
\hline Element & $\begin{array}{c}\text { Saturation Capacity } \\
\text { (g/kg adsorbent) }\end{array}$ & $\begin{array}{c}\text { 56-day } \\
\text { Adsorption } \\
\text { Capacity1,2 } \\
\text { (g/kg adsorbent) }\end{array}$ & $\begin{array}{c}\text { Half Saturation } \\
\text { Time }^{1,2} \\
\text { (days) }\end{array}$ \\
\hline $\mathrm{U}$ & $7.05 \pm 0.21$ & $5.00 \pm 0.15$ & $22.9 \pm 1.70$ \\
\hline V & $43.7 \pm 6.0$ & $20.0 \pm 2.7$ & $66.6 \pm 14.6$ \\
\hline $\mathrm{Fe}$ & $16.6 \pm 4.1$ & $5.81 \pm 1.44$ & $104 \pm 37$ \\
\hline $\mathrm{Ni}$ & $0.34 \pm 0.02$ & $0.34 \pm 0.02$ & $0.12 \pm 0.76$ \\
\hline $\mathrm{Zn}$ & $1.49 \pm 0.059$ & $1.44 \pm 0.057$ & $2.00 \pm 0.84$ \\
\hline $\mathrm{Cu}$ & $>100$ & ND & $>1000$ \\
\hline
\end{tabular}

${ }^{1}$ Determined at a temperature of $20^{\circ} \mathrm{C}$

${ }^{2}$ Normalized to a salinity of 35

\subsubsection{ORNL Al Series Adsorbents}

The ORNL AI series adsorbents were prepared by RIGP of acrylonitrile and vinylphosphonic acid onto high surface area polyethylene fibers. The various formulations had different degrees of grafting and varying mole ratios of monomer and co-monomer. Details of the preparation of the AI series of adsorbents are described in Das et al., (2016). The AI8 adsorbent was one of the 
PNNL-25899

formulations used to study the effects of temperature on adsorption capacity, which was detailed in a previous milestone report (Gill et al., 2014). The results obtained for the $20{ }^{\circ} \mathrm{C}$ experiment are given in Figure 11 and one-site ligand saturation modelling of the time series results are given in Table 4.

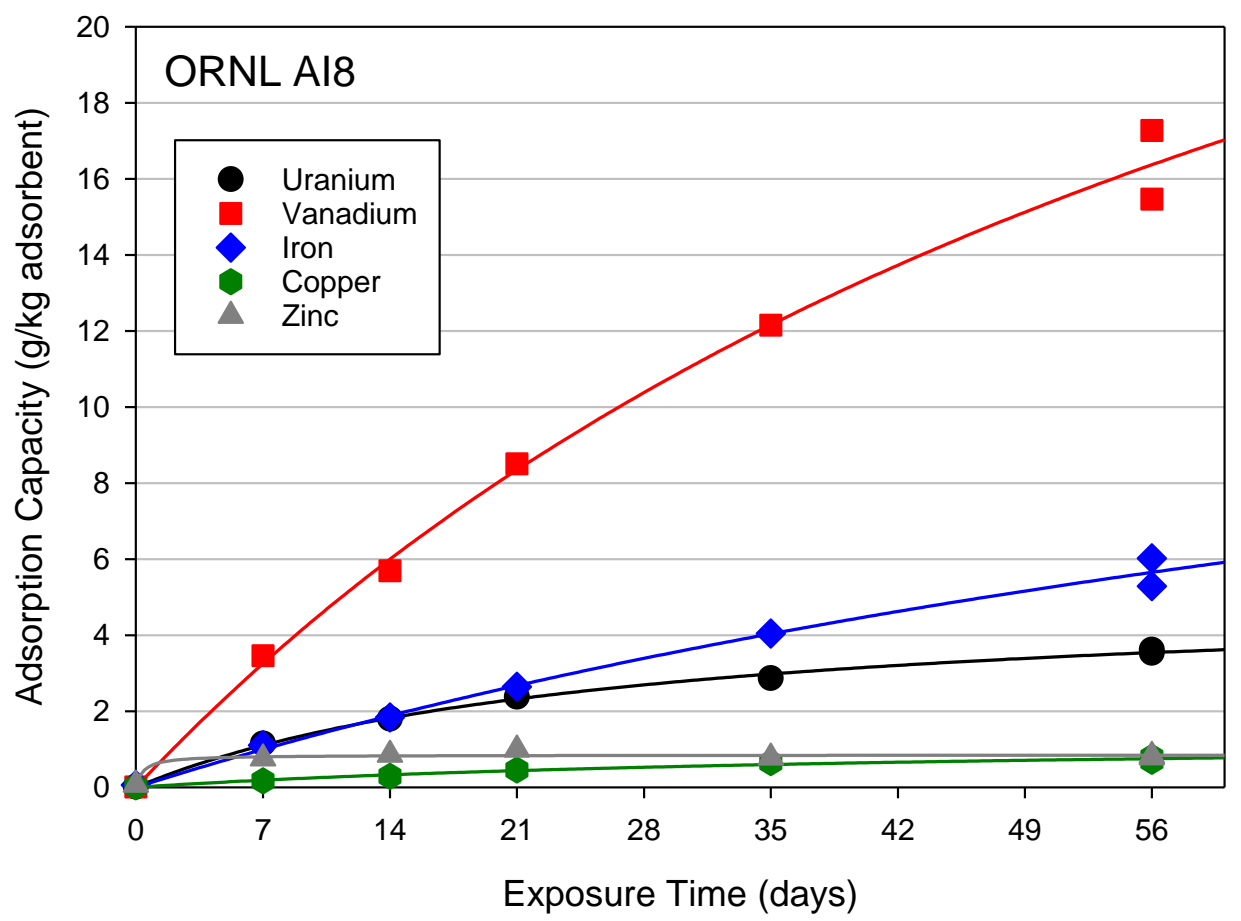

Figure 11. Time Series measurements of adsorption capacity for the ORNL adsorbent AI8 at 20 ${ }^{\circ} \mathrm{C}$ using filtered Sequim Bay seawater and a flow-through column exposure. The best fit line drawn through the data points was determined using one-site ligand saturation modelling. All data were normalized to a salinity of 35 .

Table 4. One-Site ligand saturation modelling of 56-day time series measurements with the ORNL AI8 adsorbent using a flow-through column exposure.

\begin{tabular}{cccc}
\hline Element & $\begin{array}{c}\text { Saturation } \\
\text { Capacity }^{\mathbf{1 , 2}} \\
\text { (g/kg adsorbent) }\end{array}$ & $\begin{array}{c}\text { 56-day Adsorption } \\
\text { Capacity }{ }^{\mathbf{1 , 2}} \\
\text { (g/kg adsorbent) }\end{array}$ & $\begin{array}{c}\text { Half Saturation } \\
\text { Time }^{\mathbf{1 , 2}} \\
\text { (days) }^{\text {(gads }}\end{array}$ \\
\hline $\mathrm{U}$ & $5.17 \pm 0.18$ & $3.54 \pm 0.12$ & $25.8 \pm 2.1$ \\
$\mathrm{~V}$ & $38.7 \pm 5.9$ & $16.4 \pm 2.5$ & $76 \pm 18$ \\
$\mathrm{Fe}$ & $17.0 \pm 4.3$ & $5.63 \pm 1.42$ & $113 \pm 40$ \\
$\mathrm{Zn}$ & $0.85 \pm 0.06$ & $0.84 \pm 0.06$ & $0.41 \pm 1.08$ \\
$\mathrm{Cu}$ & $1.33 \pm 0.21$ & $0.75 \pm 0.12$ & $43 \pm 13$ \\
\hline
\end{tabular}

${ }^{1}$ Determined at a temperature of $20^{\circ} \mathrm{C}$

${ }^{2}$ Normalized to a salinity of 35 
PNNL-25899

\subsubsection{New Formulations of Amidoxime-based Adsorbents from ORNL}

ORNL has been developing new amidoxime-based adsorbents that are produced by RIGP with high density polyethylene fiber, but use new monomers and/or new co-monomers as well as variations in RIGP beam, intensity and amidoximation solvents. Marine testing has been conducted with the three formulations described below

\subsubsection{ORNL AN/MA/42kGY-a1}

The ORNL adsorbent AN/MA/42kGY-a1 was prepared by RIGP with acrylonitrile and methyl acrylate, with amidoximation in DMSO. The e-beam radiation intensity used for the RIGP was $42 \mathrm{kGY}$, instead of the normal $200 \mathrm{kGY}$. Time series adsorption capacities for this material are given in Figure 12 and one-site ligand saturation modelling of uranium and selected trace elements are given in Table 5.

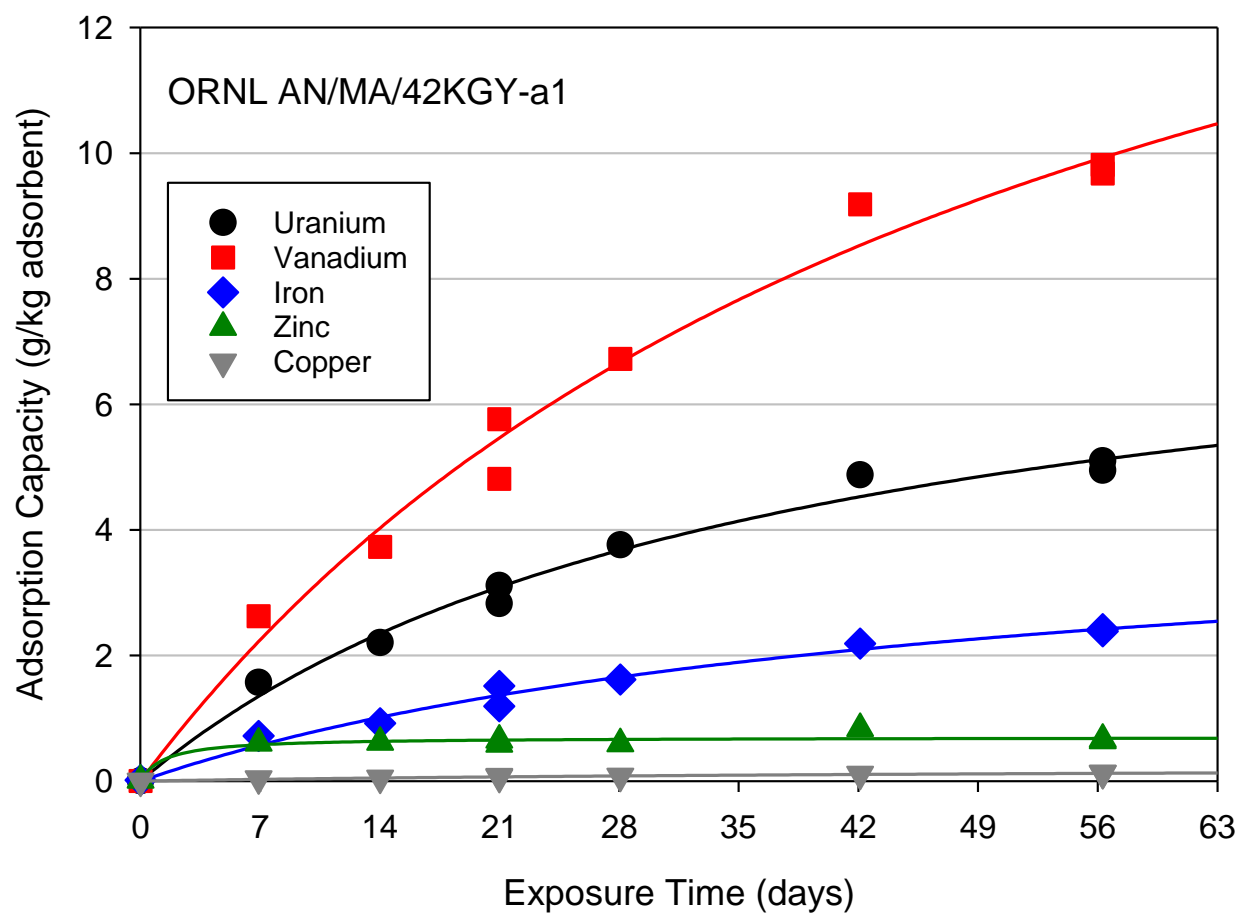

Figure 12. Time Series measurements of adsorption capacity for the ORNL adsorbent AN/MA/42kGYa1 at $20{ }^{\circ} \mathrm{C}$ using filtered Sequim Bay seawater and a flow-through column exposure. The best fit line drawn through the data points was determined using one-site ligand saturation modelling. All data were normalized to a salinity of 35 . 
PNNL-25899

Table 5. One-site ligand saturation modelling of 56-day time series adsorption capacity measurements with the ORNL AN/MA/42kGY-a1 adsorbent using a flow-through column exposure with filtered Sequim Bay seawater.

\begin{tabular}{|c|c|c|c|}
\hline Element & $\begin{array}{c}\text { Saturation } \\
\text { Capacity }^{1,2} \\
\text { (g/kg adsorbent) }\end{array}$ & $\begin{array}{c}\text { 56-day Adsorption } \\
\text { Capacity } 1,2 \\
\text { (g/kg adsorbent) }\end{array}$ & $\begin{array}{c}\text { Half Saturation } \\
\text { Time }^{1,2} \\
\text { (days) }\end{array}$ \\
\hline $\mathrm{U}$ & $8.43 \pm 0.72$ & $5.13 \pm 0.44$ & $36 \pm 6.1$ \\
\hline V & $19.3 \pm 2.3$ & $9.92 \pm 1.18$ & $53 \pm 11$ \\
\hline $\mathrm{Fe}$ & $4.47 \pm 0.55$ & $2.41 \pm 0.30$ & $48 \pm 11$ \\
\hline $\mathrm{Zn}$ & $0.69 \pm 0.05$ & $0.67 \pm 0.05$ & $1.4 \pm 1.4$ \\
\hline $\mathrm{Cu}$ & $0.24 \pm 0.03$ & $0.12 \pm 0.02$ & $56 \pm 13$ \\
\hline
\end{tabular}

${ }^{1}$ Determined at a temperature of $20^{\circ} \mathrm{C}$

${ }^{2}$ Normalized to a salinity of 35

\subsubsection{ORNL MAN1-AO/DMSO}

The ORNL adsorbent MAN1-AO/DMSO is a variant of the AF series adsorbents. It was prepared by RIGP with methacrylonitrile and itaconic acid using the same mole ratio of both monomers as was used with the AF1 adsorbent. The amidoximation was conducted in DMSO. Time series adsorption capacities for Uranium and selected trace elements using this adsorption material are given in Figure 13 and one-site ligand saturation modelling of uranium and selected trace elements are given in Table 6. 
PNNL-25899

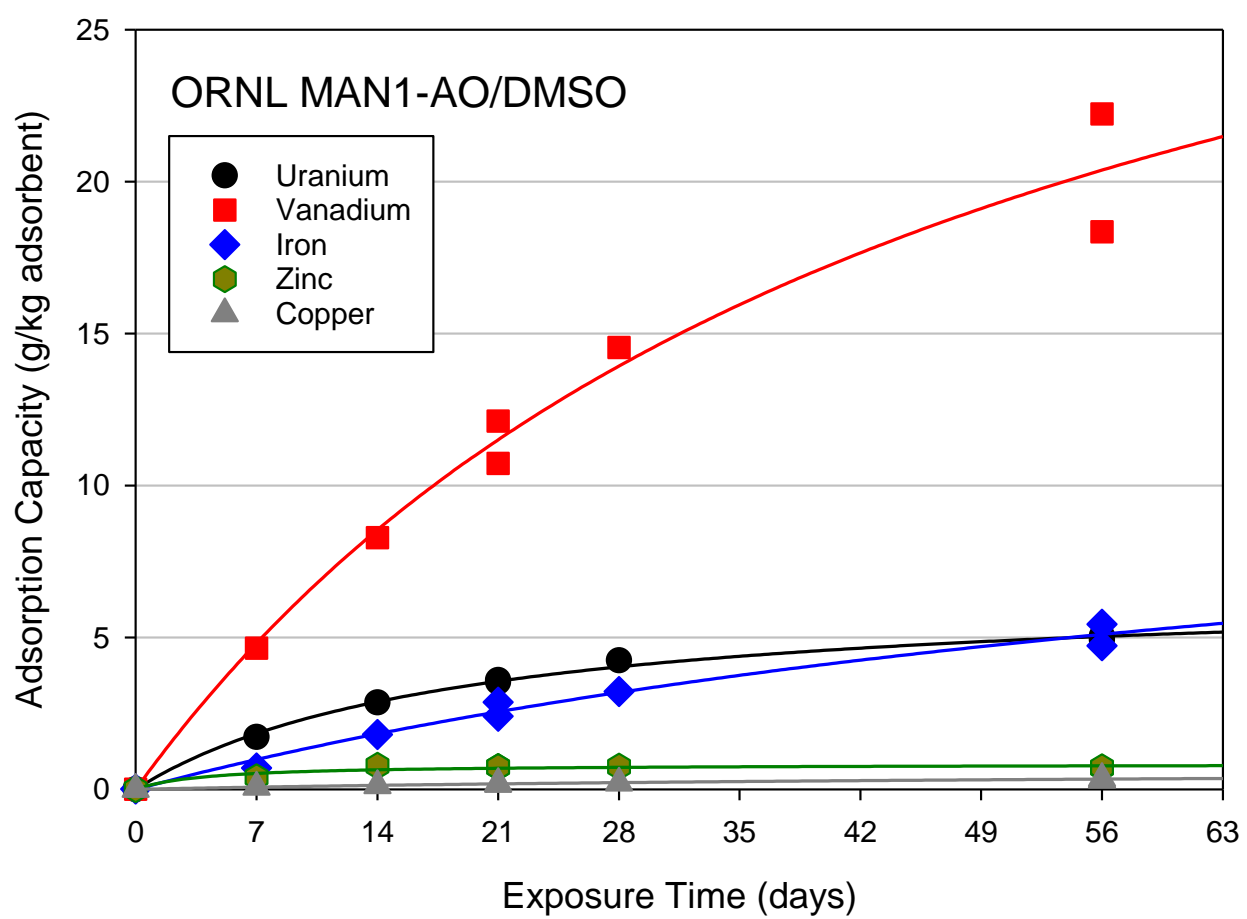

Figure 13. Time Series measurements of adsorption capacity for the ORNL adsorbent MAN1$\mathrm{AO} / \mathrm{DMSO}$ at $20{ }^{\circ} \mathrm{C}$ using filtered Sequim Bay seawater and a flow-through column exposure. The best fit line drawn through the data points was determined using one-site ligand saturation modelling. All data were normalized to a salinity of 35 .

Table 6. One-site ligand saturation modelling of 56-day time series adsorption capacity measurements with the ORNL MAN1-AO/DMSO adsorbent using a flow-through column exposure with filtered Sequim Bay seawater.

\begin{tabular}{|c|c|c|c|}
\hline Element & $\begin{array}{c}\text { Saturation } \\
\text { Capacity } 1,2 \\
\text { (g/kg adsorbent) }\end{array}$ & $\begin{array}{c}\text { 56-day Adsorption } \\
\text { Capacity } 1,2 \\
\text { (g/kg adsorbent) }\end{array}$ & $\begin{array}{c}\text { Half } \\
\text { Saturation } \\
\text { Time }^{1,2} \\
\text { (days) }\end{array}$ \\
\hline $\mathrm{U}$ & $6.70 \pm 0.22$ & $5.04 \pm 0.16$ & $18.5 \pm 1.6$ \\
\hline V & $37.9 \pm 6.0$ & $20.4 \pm 3.2$ & $48 \pm 13$ \\
\hline $\mathrm{Fe}$ & $12.7 \pm 2.8$ & $5.08 \pm 1.12$ & $84 \pm 27$ \\
\hline $\mathrm{Zn}$ & $0.83 \pm 0.08$ & $0.77 \pm 0.08$ & $4.1 \pm 2.3$ \\
\hline $\mathrm{Cu}$ & $0.710 \pm 0.12$ & $0.33 \pm 0.06$ & $62 \pm 16$ \\
\hline
\end{tabular}

${ }^{1}$ Determined at a temperature of $20^{\circ} \mathrm{C}$

${ }^{2}$ Normalized to a salinity of 35

\subsubsection{ORNL MAN8-AO/DMSO}

The ORNL adsorbent MAN8-AO/DMSO was prepared by RIGP with methacrylonitrile and itaconic acid using the same mole ratio of both monomers as was used with the AF8 adsorbent. The amidoximation was conducted in DMSO. Time series adsorption capacities for Uranium and 
PNNL-25899

selected trace elements using this adsorption material are given in Figure 14 and one-site ligand saturation modelling of uranium and selected trace elements are given in Table 7.

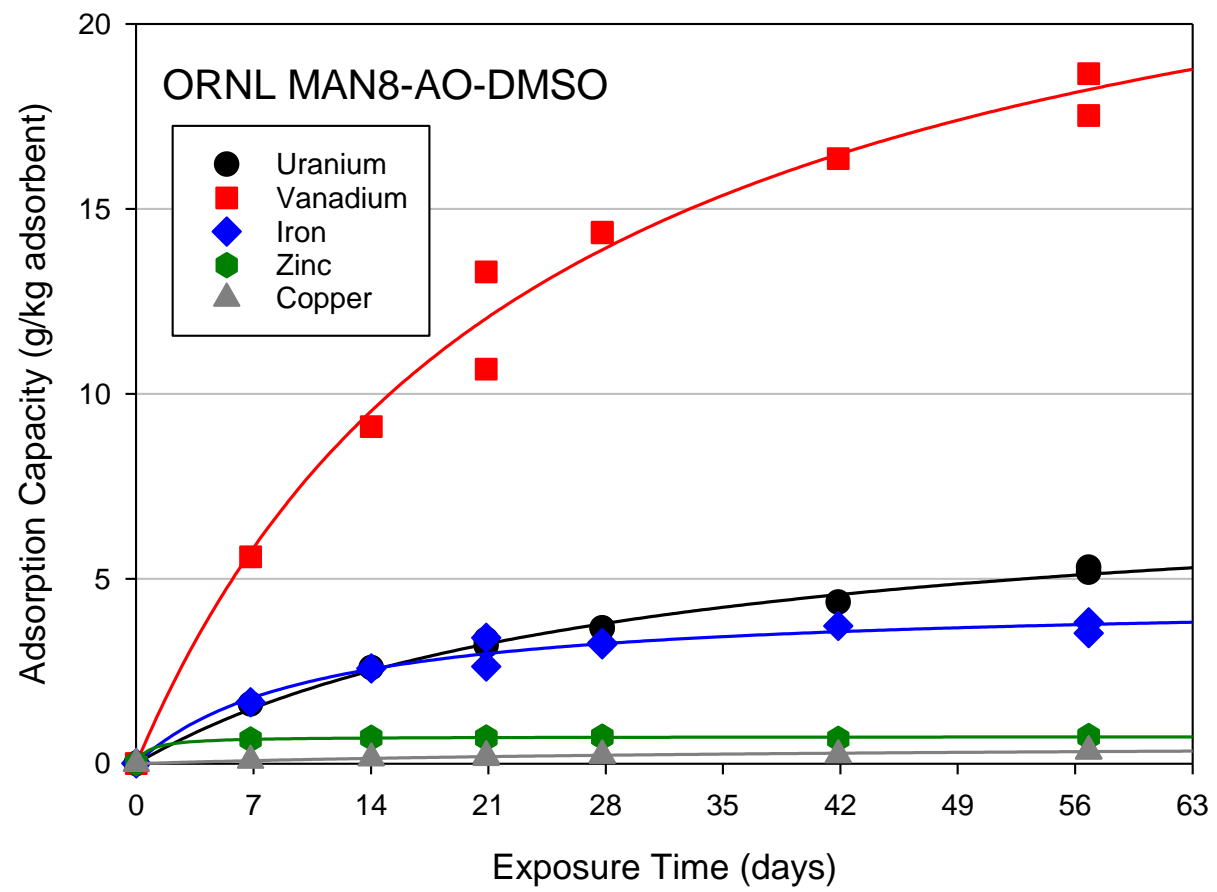

Figure 14. Time Series measurements of adsorption capacity for the ORNL adsorbent MAN8AO/DMSO at $20^{\circ} \mathrm{C}$ using filtered Sequim Bay seawater and a flow-through column exposure. The best fit line drawn through the data points was determined using one-site ligand saturation modelling. All data were normalized to a salinity of 35 .

Table 7. One-site ligand saturation modelling of 56-day time series adsorption capacity measurements with the ORNL MAN8-AO/DMSO adsorbent using a flow-through column exposure with filtered Sequim Bay seawater.

\begin{tabular}{cccc}
\hline Element & $\begin{array}{c}\text { Saturation } \\
\text { Capacity } \\
\text { (g/kg adsorbent) }\end{array}$ & $\begin{array}{c}\text { 56-day Adsorption } \\
\text { Capacity } \\
\text { (g/kg adsorbent) }\end{array}$ & $\begin{array}{c}\text { Half Saturation } \\
\text { Time } \\
\text { (days) }\end{array}$ \\
\hline $\mathrm{U}$ & $7.75 \pm 0.37$ & $5.09 \pm 0.24$ & $29.2 \pm 3.0$ \\
$\mathrm{~V}$ & $26.0 \pm 1.8$ & $18.2 \pm 1.3$ & $24.1 \pm 3.8$ \\
$\mathrm{Fe}$ & $4.45 \pm 0.28$ & $3.75 \pm 0.24$ & $10.4 \pm 2.3$ \\
$\mathrm{Zn}$ & $0.73 \pm 0.01$ & $0.72 \pm 0.01$ & $0.77 \pm 0.31$ \\
$\mathrm{Cu}$ & $0.56 \pm 0.08$ & $0.32 \pm 0.05$ & $41 \pm 12$ \\
\hline
\end{tabular}

\subsubsection{LCW Adsorbents}

Dr. Chien Wai, owner of the company LCW Supercritical Technologies, and also a retired faculty from the University of Idaho, in collaboration with Dr. Horng-bin Pan of the University of Idaho are developing amidoxime-based adsorbent materials using polyacrylonitrile (PAN) fibers. These adsorbent materials will hereafter be referred to collectively as LCW adsorbents. 
PNNL-25899

An invention disclosure has been submitted to the U. S. Patent and Trademark Office (application number 15/179,766, Filing date: June 10, 2016). The LCW adsorbents contain the amidoxime functional group and the co-monomer carboxylic acid.

\subsubsection{LCW-2 Adsorbent}

Time series measurements of adsorption capacity for uranium and selected trace elements (V, $\mathrm{Fe}, \mathrm{Zn}, \mathrm{Ni}$, and $\mathrm{Cu}$ ) with the $\mathrm{LCW}$ adsorbent $\mathrm{LCW}-2$ at $20{ }^{\circ} \mathrm{C}$ using a flow-through column exposure with filtered Sequim Bay seawater is given in Figure 15. One-site Ligand saturation modeling of the time series data is given in Table 8. This adsorbent material was developed using a commercially available knitting yarn that contained the PAN fiber called Orlon ${ }^{\mathrm{TM}}$. Note that the V/U mass ratio for this adsorbent is low compared to the ORNL adsorbents.

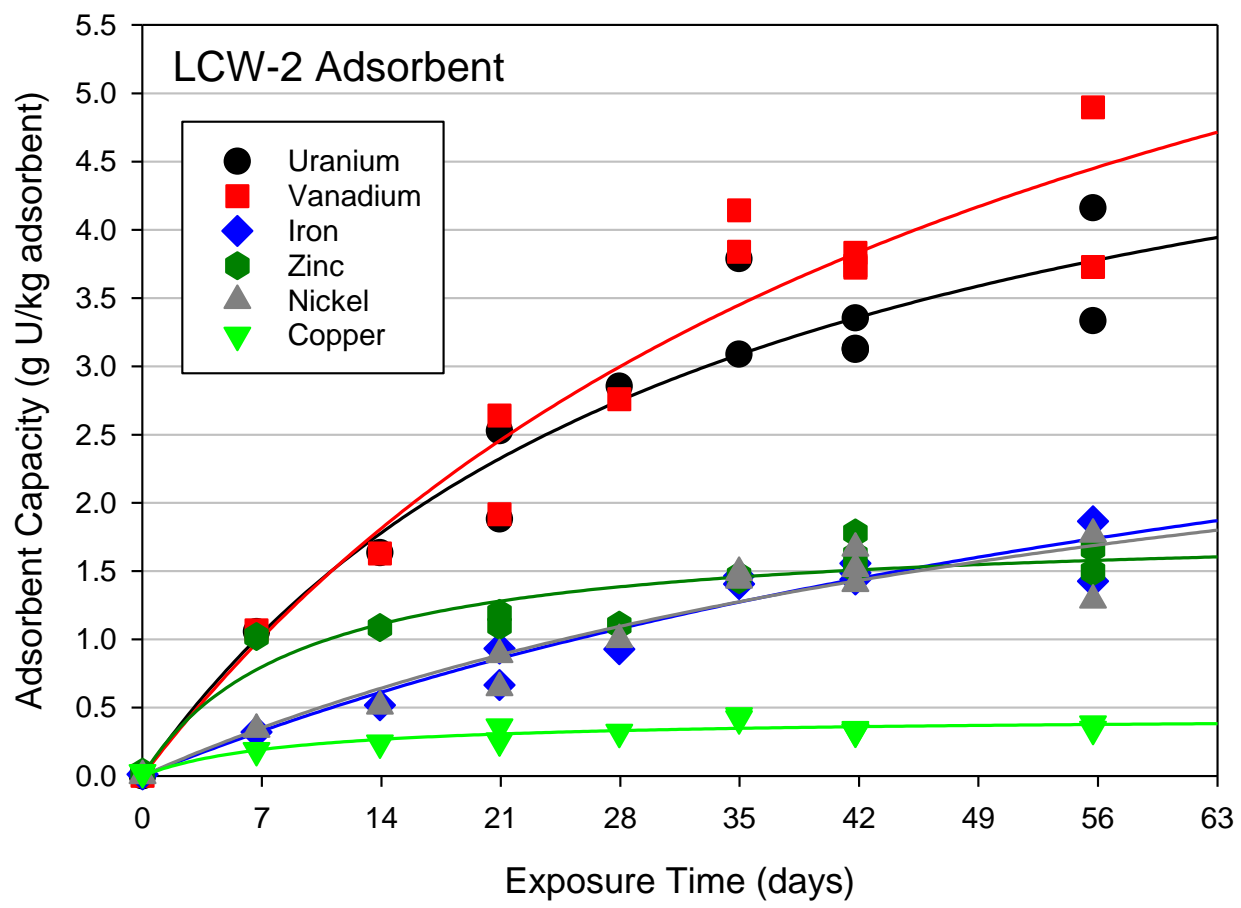

Figure 15. Time series measurements of adsorption capacity for uranium and selected trace elements with the LCW adsorbent LCW-2 at $20{ }^{\circ} \mathrm{C}$ using a flow-through column exposure with filtered Sequim Bay seawater. The best fit line drawn through the data points was determined using one-site ligand saturation modelling. All data were normalized to a salinity of 35 . 
PNNL-25899

Table 8. One-site ligand saturation modelling of the 56-day time series data for uranium and selected trace elements for the adsorbent LCW-2.

\begin{tabular}{|c|c|c|c|}
\hline Element & $\begin{array}{c}\text { Saturation } \\
\text { Capacity }^{1,2} \\
\text { (g U/kg adsorbent) }\end{array}$ & $\begin{array}{l}\text { 56-day Adsorption } \\
\text { Capacity } 1,2 \\
\text { (g U/kg adsorbent) }\end{array}$ & $\begin{array}{c}\text { Half Saturation } \\
\text { Time }^{1,2} \\
\text { (days) }\end{array}$ \\
\hline$\overline{\mathrm{U}}$ & $6.04 \pm 1.04$ & $3.78 \pm 0.65$ & $33.5 \pm 12.0$ \\
\hline V & $8.70 \pm 2.17$ & $4.47 \pm 1.11$ & $53 \pm 23$ \\
\hline $\mathrm{Fe}$ & $4.51 \pm 1.66$ & $1.74 \pm 0.64$ & $89 \pm 48$ \\
\hline $\mathrm{Ni}$ & $3.70 \pm 1.36$ & $1.68 \pm 0.62$ & $67 \pm 39$ \\
\hline $\mathrm{Zn}$ & $1.84 \pm 0.16$ & $1.58 \pm 0.14$ & $9.1 \pm 3.4$ \\
\hline $\mathrm{Cu}$ & $0.44 \pm 0.047$ & $0.38 \pm 0.04$ & $8.8 \pm 4.1$ \\
\hline
\end{tabular}

${ }^{1}$ Determined at a temperature of $20^{\circ} \mathrm{C}$

${ }^{2}$ Normalized to a salinity of 35

\subsubsection{LCW-MSL-10 Adsorbent}

The next major advancement in the LCW series resulted from optimizing the ratio of the monomer and co-monomer. Additional optimization was achieved by varying the time, temperature, and reagent concentration of the amidoximation reaction. Time series measurements of adsorption capacity for uranium and selected trace elements (V, Fe, $\mathrm{Zn}, \mathrm{Ni}$, and $\mathrm{Cu}$ ) with the LCW adsorbent LCW-MSL-10 at $20{ }^{\circ} \mathrm{C}$ using a flow-through column exposure with filtered Sequim Bay seawater is given in Figure 16. One-site Ligand saturation modeling of the time series data is given in Table 9. 
PNNL-25899

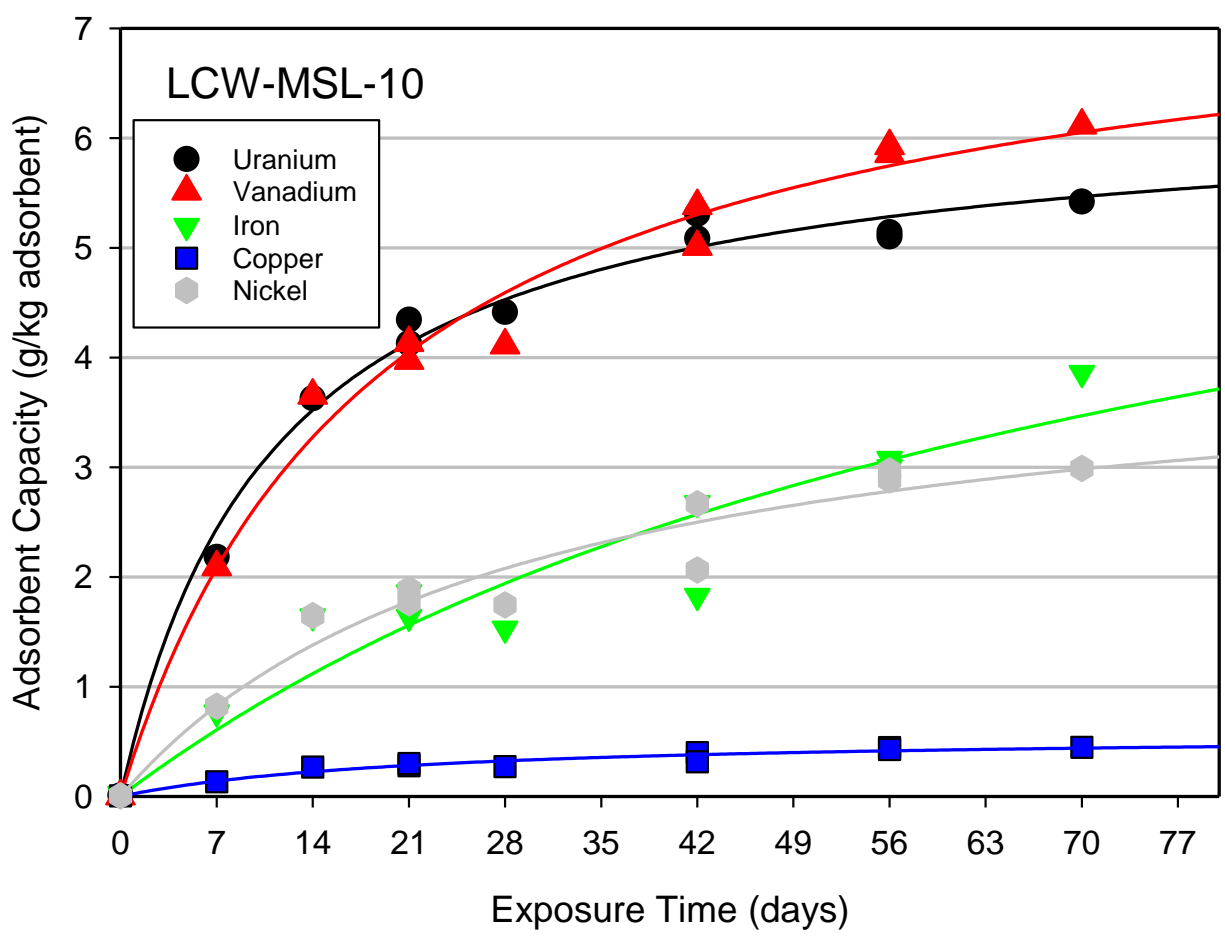

Figure 16. Time series measurements of adsorption capacity for uranium and selected trace elements with the LCW adsorbent LCW-MSL-10 at $20^{\circ} \mathrm{C}$ using a flow-through column exposure with filtered Sequim Bay seawater. The best fit lines drawn through the data points were determined using one-site ligand saturation modelling. All data were normalized to a salinity of 35 .

Table 9. One-site ligand saturation modelling of the 70-day time series data for uranium and selected trace elements for the adsorbent LCW-MSL-10

\begin{tabular}{cccc}
\hline Element & $\begin{array}{c}\text { Saturation } \\
\text { Capacity }^{\mathbf{1 , 2}} \\
\text { (g U/kg adsorbent) }\end{array}$ & $\begin{array}{c}\text { 56-day Adsorption } \\
\text { Capacity }^{\mathbf{1 , 2}} \\
\text { (g U/kg adsorbent) }\end{array}$ & $\begin{array}{c}\text { Half Saturation }_{\text {Time }^{\mathbf{1 , 2}}} \\
\text { (days) }\end{array}$ \\
\hline $\mathrm{U}$ & $6.34 \pm 0.19$ & $5.28 \pm 0.16$ & $11.2 \pm 1.3$ \\
$\mathrm{~V}$ & $7.68 \pm 0.37$ & $5.75 \pm 0.28$ & $18.8 \pm 2.6$ \\
$\mathrm{Fe}$ & $7.31 \pm 2.65$ & $3.08 \pm 1.12$ & $77 \pm 45$ \\
$\mathrm{Ni}$ & $4.21 \pm 0.50$ & $2.78 \pm 0.33$ & $28.7 \pm 8.0$ \\
$\mathrm{Zn}$ & $0.751 \pm 0.085$ & $0.75 \pm 0.08$ & $<0.1$ \\
$\mathrm{Cu}$ & $0.579 \pm 0.060$ & $0.415 \pm 0.043$ & $22.2 \pm 6.1$ \\
\hline
\end{tabular}

${ }^{1}$ Determined at a temperature of $20^{\circ} \mathrm{C}$

${ }^{2}$ Normalized to a salinity of 35

\subsubsection{University of Tennessee/ORNL SB Series Adsorbents}

Suree Brown of the University of Tennessee (UT), in collaboration with scientists at ORNL prepared uranium adsorption materials using atom-transfer radical polymerization (ATRP) on a variety of polymers including polypropylene, polyethylene and poly(vinyl chloride)-cochlorinated poly(vinyl chloride) (PVC-co-CPVC) fiber (Brown et al 2016a, 2016b). Two 
adsorbents that show the most promise that have undergone time series flow-through column testing to date are SB11-295 and SB12-8. Time series plots of adsorption capacity are shown in Figures 17 and 18 for the adsorbents SB11-295 and SB12-8, respectively. A direct comparison of the time series adsorption capacity measurements for the two adsorbents is given in Figure 19. One-site ligand saturation modelling of the time series data is given in Table 10.

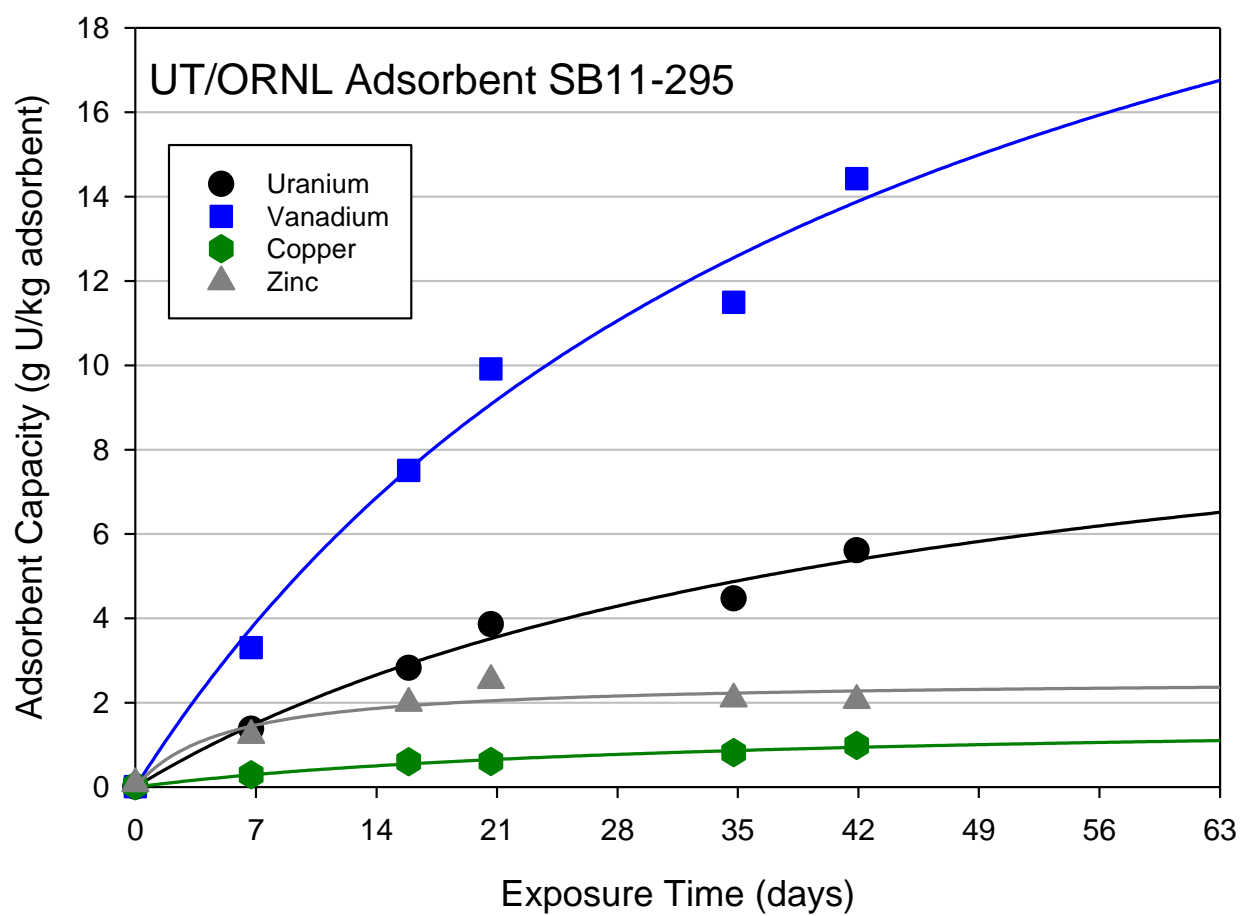

Figure 17. Time Series measurements of adsorption capacity for the UT/ORNL adsorbent SB11-295 at $20{ }^{\circ} \mathrm{C}$ using filtered Sequim Bay seawater and a flow-through column exposure. The best fit line drawn through the data points was determined using one-site ligand saturation modelling. All data were normalized to a salinity of 35 . 
PNNL-25899

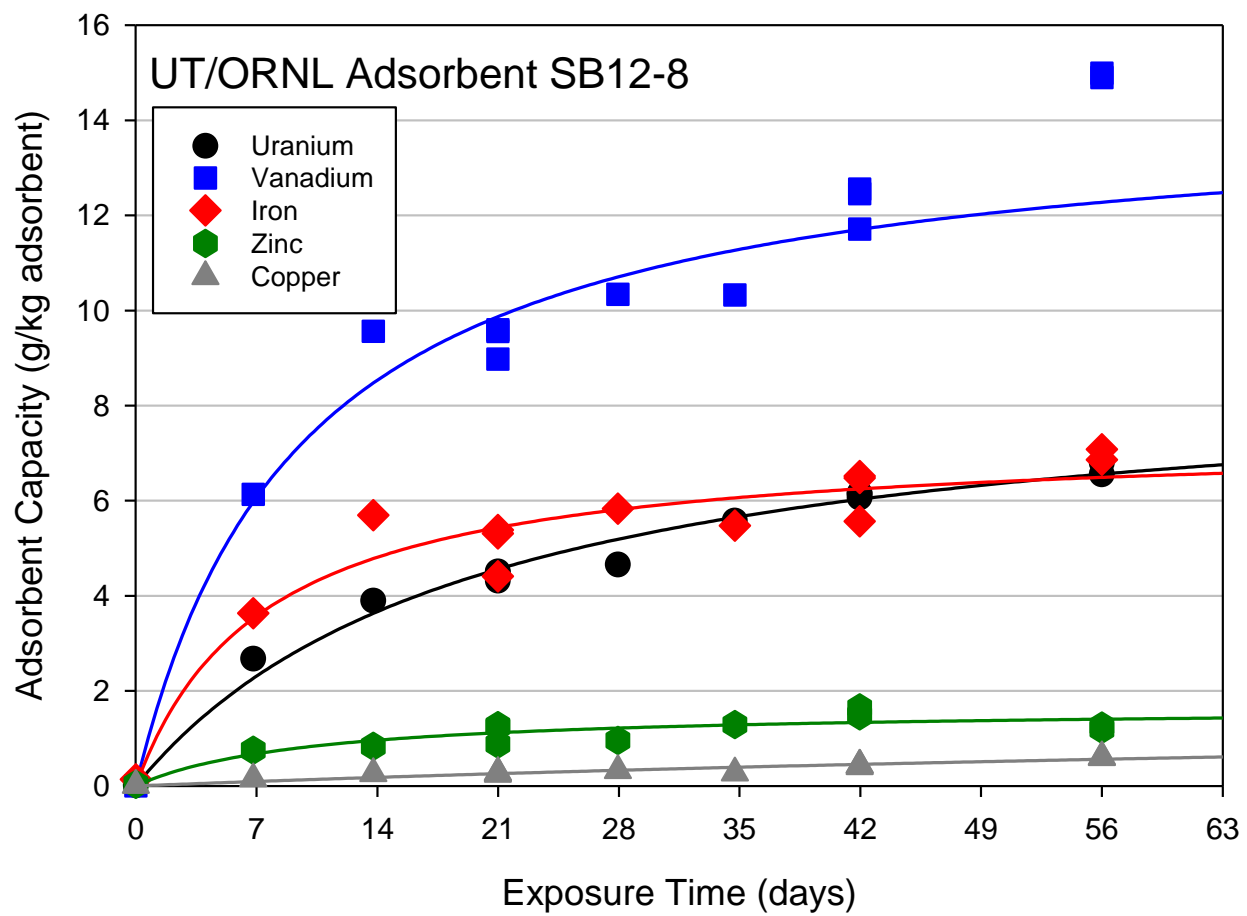

Figure 18. Time Series measurements of adsorption capacity for the UT/ORNL adsorbent SB12-8 at 20 ${ }^{\circ} \mathrm{C}$ using filtered Sequim Bay seawater and a flow-through column exposure. The best fit line drawn through the data points was determined using one-site ligand saturation modelling. All data were normalized to a salinity of 35 . 
PNNL-25899

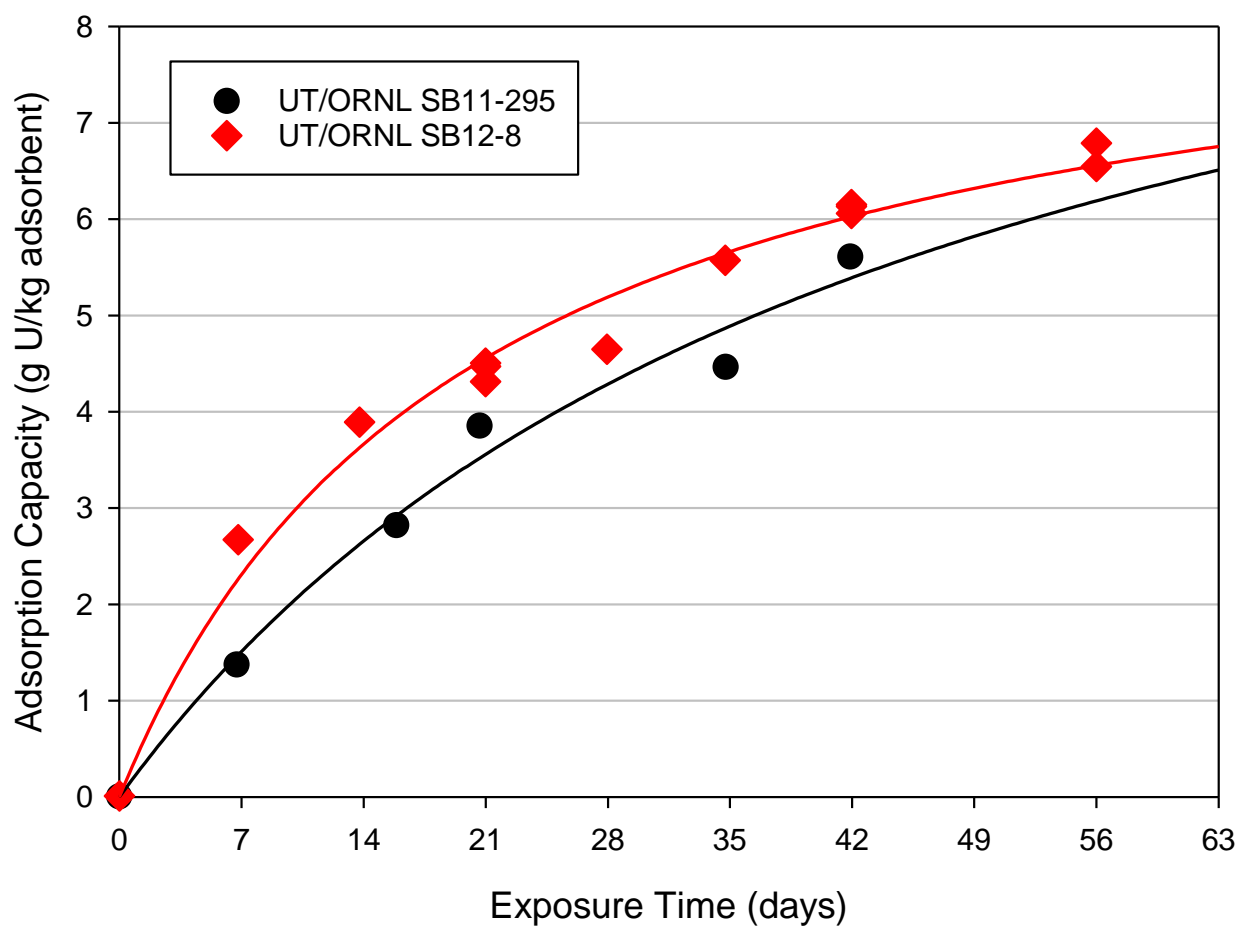

Figure 19. Comparison of time series measurements of adsorption capacity for the UT/ORNL adsorbents SB11-295 and SB12-8 at $20{ }^{\circ} \mathrm{C}$ using filtered Sequim Bay seawater and a flow-through column exposure. The best fit line drawn through the data points was determined using one-site ligand saturation modelling.

All data were normalized to a salinity of 35 .

Table 10. One-Site ligand saturation modelling of two adsorbent materials prepared by atomtransfer radical polymerization using flow-through column exposures

\begin{tabular}{|c|c|c|c|}
\hline Adsorbent & $\begin{array}{c}\text { 56-day Adsorption } \\
\text { Capacity } 1,2 \\
\text { (g U/kg adsorbent) }\end{array}$ & $\begin{array}{c}\text { Adsorption } \\
\text { Capacity }{ }^{1,2} \\
\text { (g U/kg adsorbent) }\end{array}$ & $\begin{array}{c}\text { Half- } \\
\text { Saturation } \\
\text { Time } \\
\text { (days) }\end{array}$ \\
\hline SB11-295 & $6.18 \pm 1.34$ & $11.1 \pm 2.4$ & $44.6 \pm 16.4$ \\
\hline SB12-8 & $6.56 \pm 0.33$ & $8.90 \pm 0.45$ & $20.0 \pm 2.65$ \\
\hline
\end{tabular}

\subsection{Recirculating Flume Exposures}

\subsubsection{Effect of Flow-rate on Adsorption Capacity}

Prior to presenting and discussing the results obtained using recirculating flume exposures, it is important to acknowledge that a study conducted in 2015 and reported in FY 2016 on the effect of flow-rate on adsorption capacity revealed that adsorption capacity was highly dependent on flow-rate (Gill et al., 2015). The 56-day adsorption capacity with the ORNL AF1 adsorbent varied from a low of $2.02 \pm 1.08 \mathrm{~g} \mathrm{U} / \mathrm{kg}$ adsorbent at a liner velocity of $0.48 \mathrm{~cm} / \mathrm{sec}$, to a high of 
$4.31 \pm 0.39 \mathrm{~g} \mathrm{U} / \mathrm{kg}$ adsorbent at a liner velocity of $5.52 \mathrm{~cm} / \mathrm{s}$, more than a two-fold difference. For the results reported here, the linear velocity was maintained between 2 and $2.5 \mathrm{~cm} / \mathrm{sec}$. This velocity was chosen to be consistent with the testing done in flow-through columns. While this flow-rate does not yield maximal adsorption capacities, it was nonetheless consistent between all the flume studies, allowing for direct comparison between individual flume tests and also comparison with the flow-through column studies.

\subsubsection{Initial Procedural Development Tests with the ORNL AF1B17-2 Adsorbent}

The first use of a recirculating flume for a time series natural seawater exposure experiment was conducted using the ORNL adsorbent AF1B17-2. A total of four braids were deployed simultaneously in a single flume and time series measurements were collected over a 42-day exposure period. The braids deployed had different weaving characteristics (picks per inch, ppi) and also different potassium hydroxide $(\mathrm{KOH})$ conditioning times to examine the effect of these parameters on adsorption performance. Two of the braids were woven with a ppi of 5 (5ppi) and two were woven with a ppi of 25 (25ppi). In addition, two of the braids were conditioned with a 2.5 weight percent $\mathrm{KOH}$ solution at $60{ }^{\circ} \mathrm{C}$ for one hour and two were $\mathrm{KOH}$ conditioned at $80{ }^{\circ} \mathrm{C}$ for one hour. The exposure was conducted with a recirculation rate in the flume of 15 gallons per minute (linear velocity estimated at $\sim 2 \mathrm{~cm} / \mathrm{s}$ ) and a fresh seawater inflow of $3 \mathrm{~L} / \mathrm{minute}$. The time series adsorption capacity measurements for these exposures are illustrated in Figure 20 and the one-site ligand saturation modelling results are given in Table 11. Measurements of uranium in the feed seawater and the flume conducted during the exposure are illustrated in Figure 21.

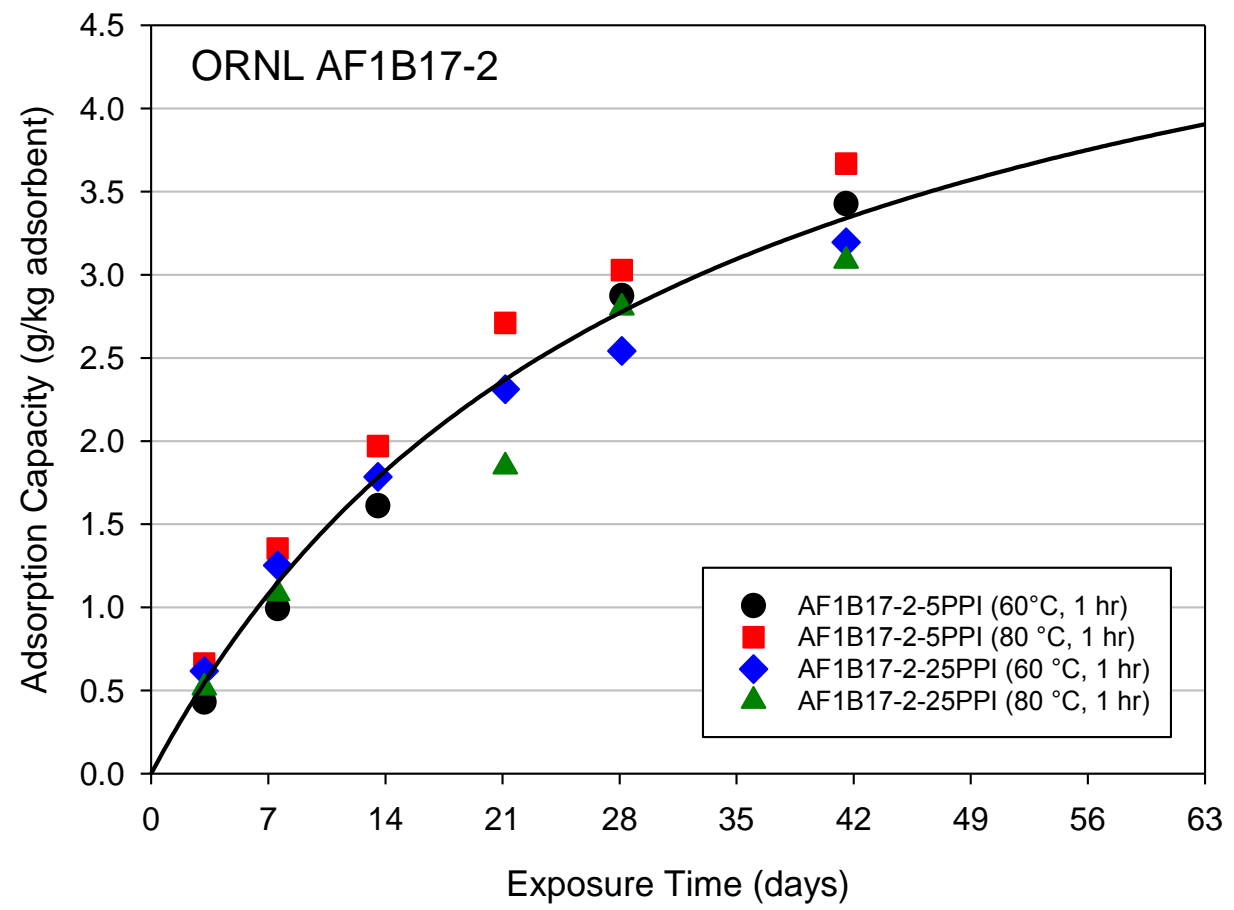

Figure 20. Time series measurements of adsorption capacity of the ORNL adsorbent AF1B17-2 using a recirculating flume exposure with natural filtered seawater. 
Table 11. One-site ligand saturation modelling of the experimental data depicted in Figure 5 for the ORNL adsorbent AF1B17-2 exposed to natural seawater in a recirculating flume.

\begin{tabular}{|c|c|c|c|c|c|}
\hline $\begin{array}{l}\text { AF1 Braid } \\
\text { Adsorbent }\end{array}$ & $\begin{array}{c}\text { КОH } \\
\text { Conditioning } \\
(2.5 \mathrm{wt} \% \\
\text { KOH }) \\
\end{array}$ & $\begin{array}{c}\text { 42-Day } \\
\text { Adsorption } \\
\text { Capacity } 1,2 \\
\text { (g U/kg } \\
\text { adsorbent) } \\
\end{array}$ & $\begin{array}{c}\text { 56-Day } \\
\text { Adsorption } \\
\text { Capacity1,2 } \\
\text { (g U/kg } \\
\text { adsorbent) } \\
\end{array}$ & $\begin{array}{c}\text { Saturation } \\
\text { Capacity } 1,2 \\
\text { (g U/kg } \\
\text { adsorbent) } \\
\end{array}$ & $\begin{array}{c}\text { Half } \\
\text { Saturation } \\
\text { Time }^{1,2} \\
\text { (days) } \\
\end{array}$ \\
\hline AF1B17-2-5ppi & 1 hr. @6 $60^{\circ} \mathrm{C}$ & $3.50 \pm 0.30$ & $4.05 \pm 0.34$ & $7.60 \pm 0.64$ & $49.1 \pm 6.6$ \\
\hline AF1B17-2-5ppi & 1 hr. @ $80^{\circ} \mathrm{C}$ & $3.67 \pm 0.12$ & $4.06 \pm 0.14$ & $5.97 \pm 0.20$ & $26.4 \pm 1.7$ \\
\hline AF1B17-2-25ppi & 1 hr. @60 $\mathrm{C}$ & $3.13 \pm 0.17$ & $3.43 \pm 0.18$ & $4.84 \pm 0.26$ & $23.0 \pm 2.6$ \\
\hline AF1B17-2-25ppi & 1 hr. @ $80^{\circ} \mathrm{C}$ & $3.14 \pm 0.80$ & $3.56 \pm 0.91$ & $5.94 \pm 1.52$ & $38 \pm 17$ \\
\hline All & & $3.36 \pm 0.30$ & $3.75 \pm 0.34$ & $5.80 \pm 0.52$ & $30.6 \pm 5.1$ \\
\hline
\end{tabular}

${ }^{1}$ Predicted using one-site ligand saturation modelling at a temperature of $20^{\circ} \mathrm{C}$

${ }^{2}$ Normalized to a salinity of 35

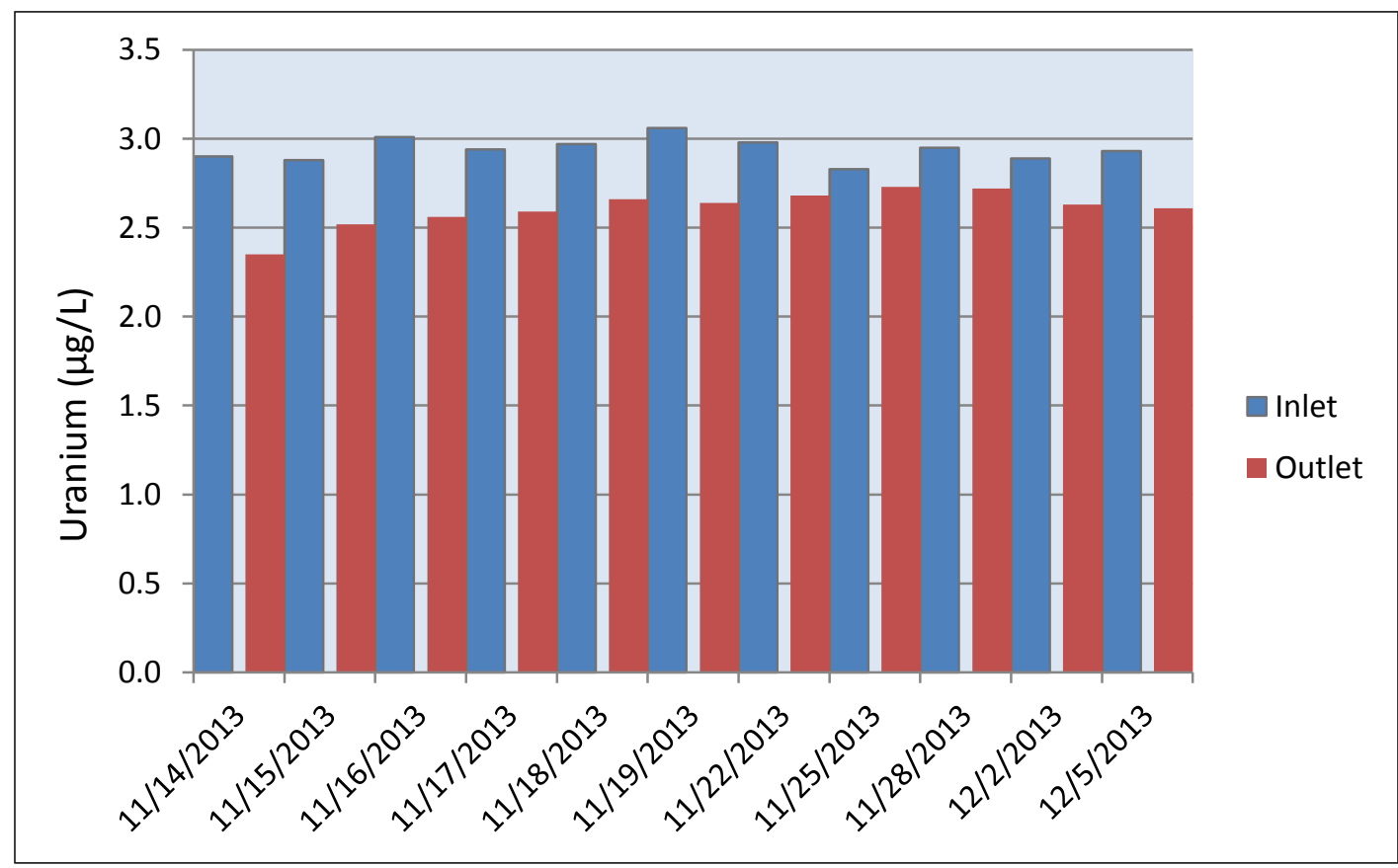

Figure 21. Uranium concentrations in the seawater entering the flume and within the flume during the first flume exposure experiment.

These initial tests to develop the procedures for exposure using a recirculating flume revealed several important operational features. First, the rate at which fresh seawater needs to be introduced into the flume is critical, and is dependent on the mass of braid being exposed. The current experiment indicated that $3 \mathrm{~L} /$ minute was insufficient to maintain the level of uranium within the flume at the same concentration in the feed water, for a total mass of braid of $32 \mathrm{~g}$ (Figure 6). Hence, the adsorption capacities for this experiment are likely lower than would be anticipated, but there is no way to determine how much of an impact this would have. Second, based on the adsorption capacities in Table 11, there was no evidence that the conditioning temperature (60 vs $80^{\circ} \mathrm{C}$ ) effected the adsorption capacity. And third, based on the adsorption 
PNNL-25899

capacities in Table 11, there is some evidence to suggest that the 25 ppi braid had a lower adsorption capacity than the braid that was woven at 5 ppi.

\subsubsection{Replicate AF1 Braid Exposure Tests}

A total of seven time series experiments were conducted using the braided ORNL adsorbent AF1 with exposure using a recirculating flume. The exposures were conducted in two separate batches during different time periods. Illustrated in Figure 22 are four separate exposures that correspond to the flow-through column exposures described previously. The fibers used for the flow-through column exposures were taken off of the adsorbents used in these flume exposures, allowing for a direct comparison for these adsorbents in both flow-through column and flume exposures. The results for three AF1L2R3 braids that were all prepared in a common batch are shown in Figure 23. The results of these 7 experiments are combined together for comparison in Figure 24. One-site ligand saturation modelling for all 7 exposures is given in Table 12.

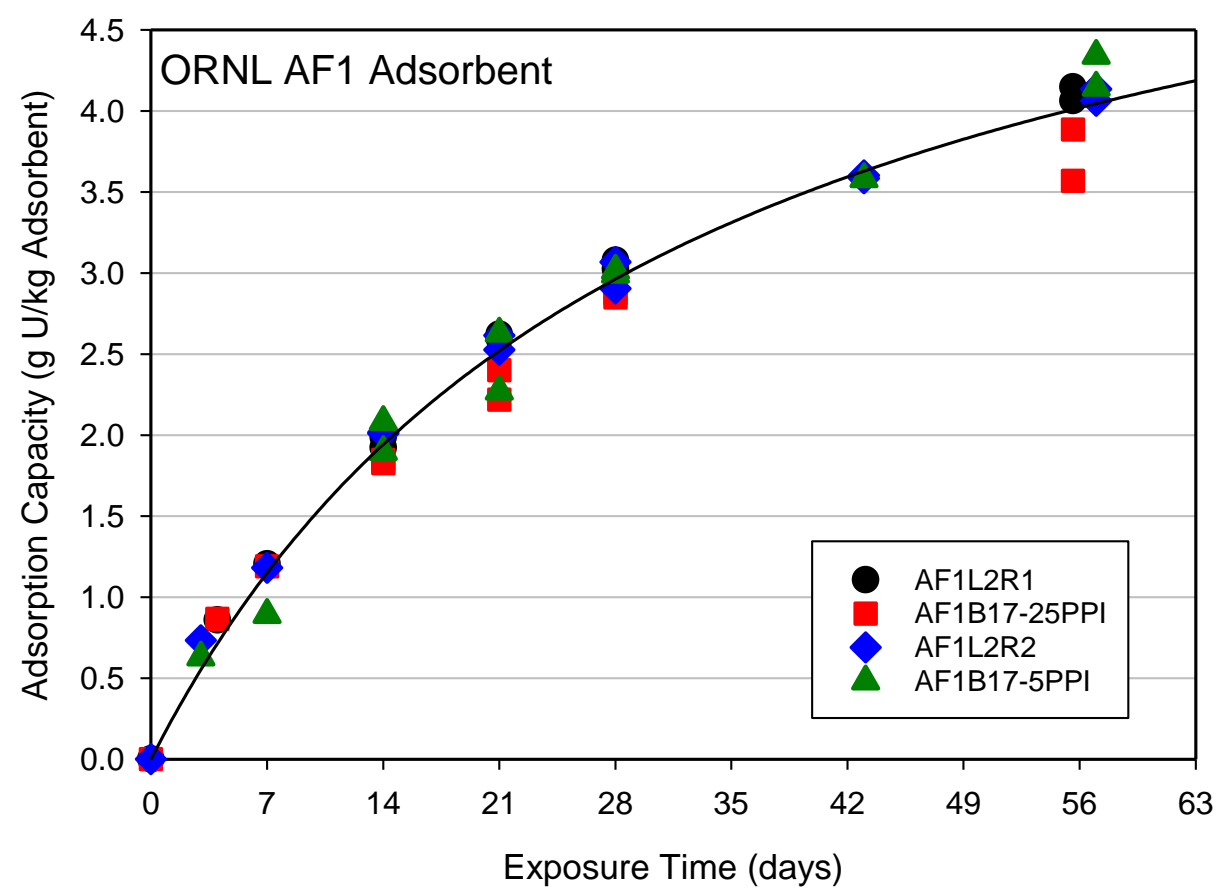

Figure 22. Time Series measurements of adsorption capacity for four separate simultaneous deployments in a recirculating flume of the ORNL adsorbent $\mathrm{AF} 1$ at $20^{\circ} \mathrm{C}$ using filtered Sequim Bay seawater. The best fit line drawn through the data points was determined using one-site ligand saturation modelling. All data were normalized to a salinity of 35 . 
PNNL-25899

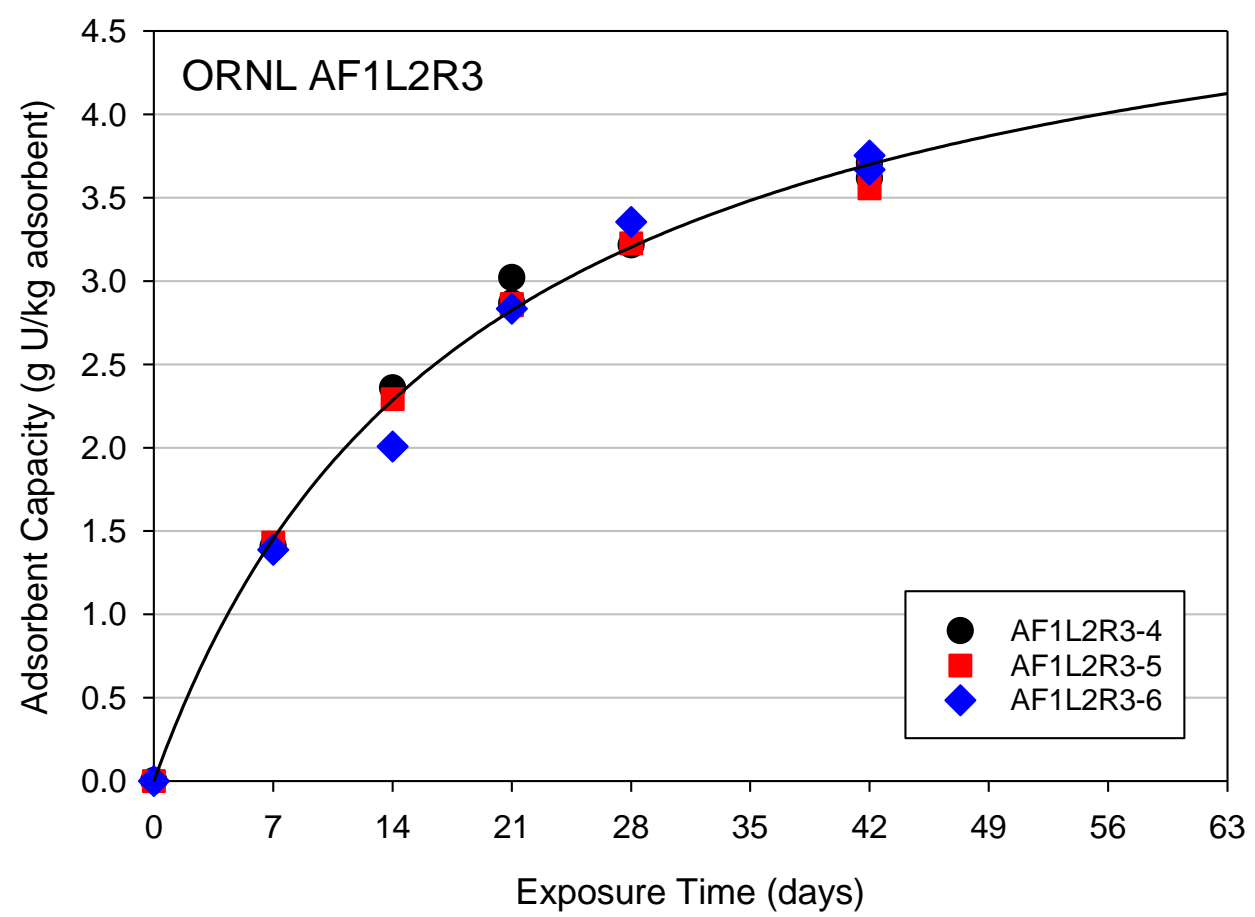

Figure 23. Time Series measurements of adsorption capacity for three separate simultaneous deployments in a recirculating flume of the ORNL adsorbent AF1 at $20{ }^{\circ} \mathrm{C}$ using filtered Sequim Bay seawater. The best fit line drawn through the data points was determined using one-site ligand saturation modelling. All data were normalized to a salinity of 35 .

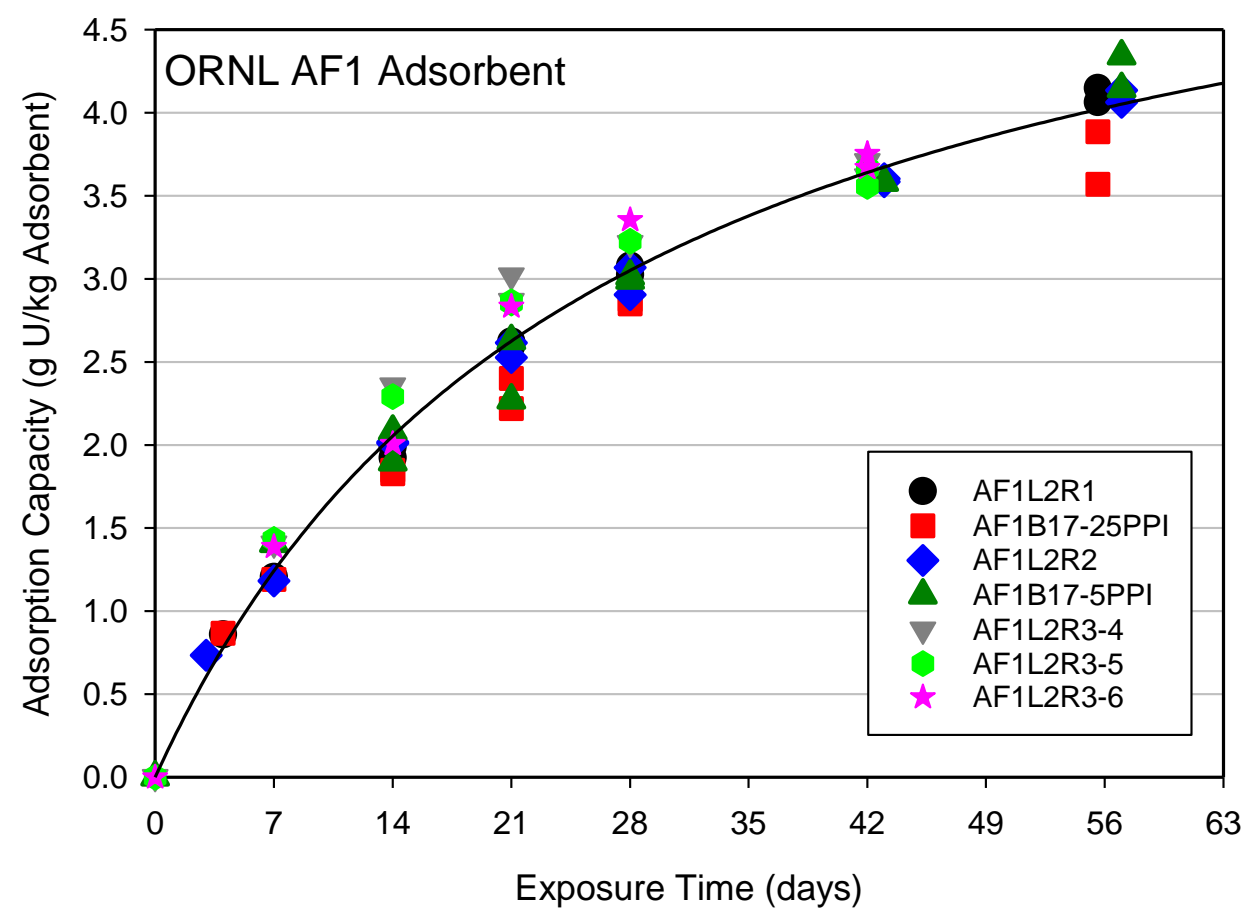

Figure 24. Time series measurements of adsorption capacity for all seven deployments of the ORNL adsorbent AF1 at $20^{\circ} \mathrm{C}$ using filtered Sequim Bay seawater. The best fit line drawn through the data points was determined using one-site ligand saturation modelling. All data were normalized to a salinity of 35 . 
PNNL-25899

Table 12. One-site ligand saturation modelling for seven separate determinations of the AF1 adsorbent using recirculating flume exposures.

\begin{tabular}{|c|c|c|c|c|}
\hline MSL ID & Adsorbent & $\begin{array}{c}\text { Saturation } \\
\text { Capacity }{ }^{1,2} \\
\text { (g U/kg adsorbent) }\end{array}$ & $\begin{array}{l}\text { 56-day Adsorption } \\
\text { Capacity1,2 } \\
\text { (g U/kg adsorbent) }\end{array}$ & $\begin{array}{c}\text { Half Saturation } \\
\text { Time }^{1,2} \\
\text { (days) }\end{array}$ \\
\hline $3439-1$ & AF1L2R1 & $6.32 \pm 0.15$ & $4.11 \pm 0.10$ & $30.1 \pm 1.44$ \\
\hline $3439-2$ & AF1B17-25PPI & $5.57 \pm 0.30$ & $3.73 \pm 0.20$ & $27.6 \pm 3.07$ \\
\hline $3439-3$ & AF1L2R2 & $6.05 \pm 0.17$ & $4.02 \pm 0.11$ & $28.3 \pm 1.72$ \\
\hline $3439-4$ & AF1B17-5PPI & $6.99 \pm 0.47$ & $4.17 \pm 0.28$ & $37.8 \pm 4.78$ \\
\hline \multicolumn{2}{|c|}{ All 3439 Data Combined } & $6.25 \pm 0.18$ & $4.02 \pm 0.12$ & $31.1 \pm 1.86$ \\
\hline $3450-4$ & AF1L2R3 & $5.19 \pm 0.20$ & $3.99 \pm 0.15$ & $16.9 \pm 1.7$ \\
\hline $3450-5$ & AF1L2R3 & $5.13 \pm 0.13$ & $3.93 \pm 0.10$ & $17.1 \pm 1.1$ \\
\hline $3450-6$ & AF1L2R3 & $5.87 \pm 0.42$ & $4.13 \pm 0.30$ & $23.5 \pm 3.7$ \\
\hline \multirow{2}{*}{\multicolumn{2}{|c|}{$\begin{array}{l}\text { All } 3450 \text { Data Combined } \\
\text { All } 3439 \text { and } 3450 \text { Data Combined }\end{array}$}} & $5.36 \pm 0.15$ & $4.01 \pm 0.11$ & $18.8 \pm 1.2$ \\
\hline & & $5.93 \pm 0.17$ & $4.03 \pm 0.12$ & $26.5 \pm 1.6$ \\
\hline
\end{tabular}

${ }^{1}$ Predicted using one-site ligand saturation modelling at a temperature of $20^{\circ} \mathrm{C}$

${ }^{2}$ Normalized to a salinity of 35

\subsection{ORNL Al8 Time Series Flume Testing}

The ORNL adsorbent AI8 was one of the formulations that were investigated in the potassium bicarbonate re-usability study. Illustrated in Figure 25 below is the time series data for the initial exposure of the braid in the flume. One site ligand saturation modelling of the AI8 time series data is given in Table 13. The exposure was only carried out for 42 days, so the 56day capacity predictions by one-site ligand saturation capacity are not as precise as the other exposures reported herein which were conducted for 56 days. 
PNNL-25899

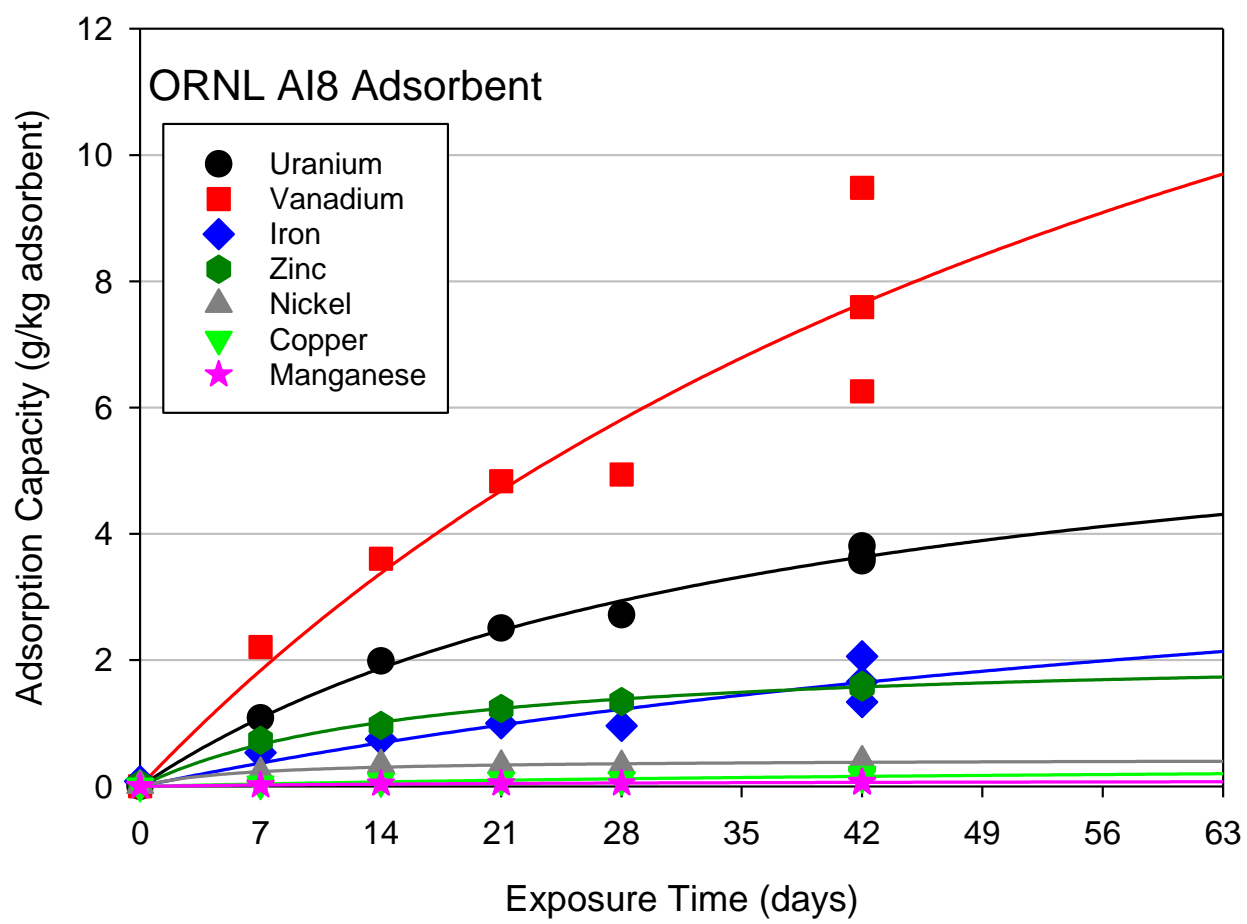

Figure 25. Time series measurements of adsorption capacity for the ORNL adsorbent $\mathrm{A} 18$ at $20{ }^{\circ} \mathrm{C}$ using filtered Sequim Bay seawater. The best fit line drawn through the data points was determined using onesite ligand saturation modelling. All data were normalized to a salinity of 35 .

Table 13. One-site ligand saturation modelling for the ORNL adsorbent AI8 using a recirculating flume exposure.

\begin{tabular}{|c|c|c|c|c|}
\hline MSL ID & Element & $\begin{array}{c}\text { Saturation } \\
\text { Capacity1,2 } \\
\text { (g U/kg adsorbent) }\end{array}$ & $\begin{array}{c}\text { 56-day Adsorption } \\
\text { Capacity1,2 } \\
\text { (g U/kg adsorbent) }\end{array}$ & $\begin{array}{c}\text { Half } \\
\text { Saturation } \\
\text { Time }^{1,2} \\
\text { (days) }\end{array}$ \\
\hline $3540-33$ & $\bar{U}$ & $6.86 \pm 0.68$ & $4.13 \pm 0.41$ & $37 \pm 7.0$ \\
\hline $3540-33$ & V & $21 \pm 14$ & $9.1 \pm 6.1$ & $73 \pm 71$ \\
\hline $3540-33$ & $\mathrm{Fe}$ & $5.3 \pm 5.1$ & $2.0 \pm 1.9$ & $94 \pm 124$ \\
\hline $3540-33$ & $\mathrm{Zn}$ & $2.2 \pm 0.1$ & $1.7 \pm 0.1$ & $16 \pm 1.8$ \\
\hline $3540-33$ & $\mathrm{Ni}$ & $0.44 \pm 0.03$ & $0.40 \pm 0.03$ & $6.1 \pm 1.8$ \\
\hline $3540-33$ & $\mathrm{Mn}$ & $0.11 \pm 0.02$ & $0.07 \pm 0.01$ & $28 \pm 12$ \\
\hline $3540-33$ & $\mathrm{Cu}$ & $0.42 \pm 0.22$ & $0.19 \pm 0.10$ & $70 \pm 54$ \\
\hline
\end{tabular}

${ }^{1}$ Predicted using one-site ligand saturation modelling at a temperature of $20^{\circ} \mathrm{C}$

${ }^{2}$ Normalized to a salinity of 35

\subsection{ORNL AF8 Time Series Flume Testing}

The ORNL adsorbent AF8 was one of the formulations that were investigated in the potassium bicarbonate re-usability study (Kuo et al., 2016). Illustrated in Figure 26 below is the 
PNNL-25899

time series data for the initial exposure of the braid in the flume. One site ligand saturation modelling of the AF8 time series data is given in Table 14.

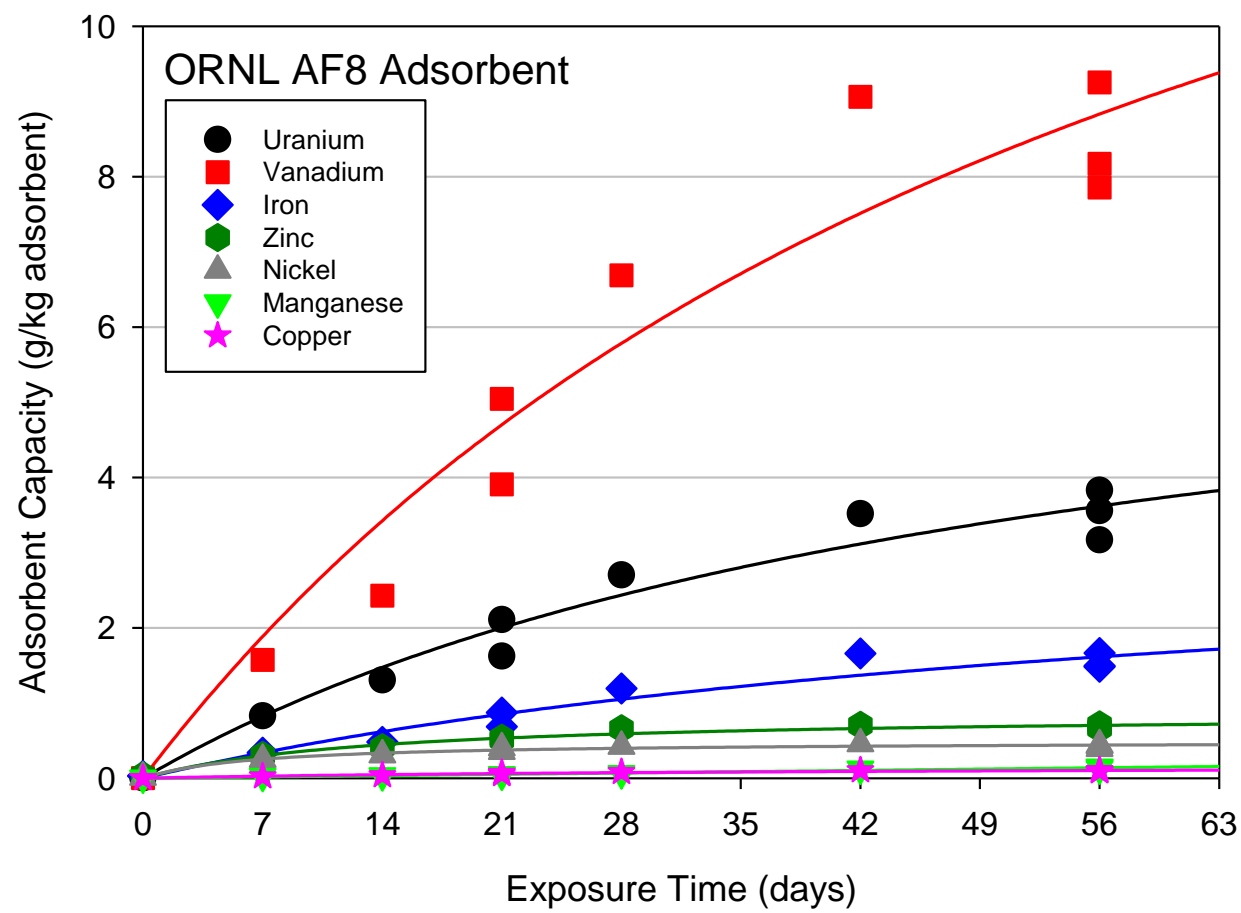

Figure 26. Time series measurements of adsorption capacity for the ORNL adsorbent AF8 at $20{ }^{\circ} \mathrm{C}$ using filtered Sequim Bay seawater. The best fit line drawn through the data points was determined using onesite ligand saturation modelling. All data were normalized to a salinity of 35 .

Table 14. One-site ligand saturation modelling for ORNL adsorbent AF8 using recirculating flume exposures.

\begin{tabular}{ccccc}
\hline MSL ID & Element & $\begin{array}{c}\text { Saturation } \\
\text { Capacity } \mathbf{1 , 2} \\
\text { (g U/kg adsorbent) }\end{array}$ & $\begin{array}{c}\text { 56-day Adsorption } \\
\text { Capacity } \mathbf{1 , 2} \\
\text { (g U/kg adsorbent) }\end{array}$ & $\begin{array}{c}\text { Half Saturation } \\
\text { Time } \mathbf{1 , 2} \\
\text { (days) }\end{array}$ \\
\hline $3540-33$ & $\mathrm{U}$ & $7.04 \pm 1.42$ & $3.62 \pm 0.73$ & $52.9 \pm 19.0$ \\
$3540-33$ & $\mathrm{~V}$ & $18.7 \pm 5.57$ & $8.84 \pm 2.63$ & $62.4 \pm 31.2$ \\
$3540-33$ & $\mathrm{Fe}$ & $3.48 \pm 0.99$ & $1.61 \pm 0.46$ & $64.9 \pm 30.4$ \\
$3540-33$ & $\mathrm{Zn}$ & $0.871 \pm 0.052$ & $0.703 \pm 0.042$ & $13.4 \pm 2.61$ \\
$3540-33$ & $\mathrm{Ni}$ & $0.492 \pm 0.024$ & $0.440 \pm 0.021$ & $6.65 \pm 1.56$ \\
$3540-33$ & $\mathrm{Mn}$ & $\mathrm{ND}$ & $\mathrm{ND}$ & $\mathrm{ND}$ \\
$3540-33$ & $\mathrm{Cu}$ & $0.170 \pm 0.031$ & $0.102 \pm 0.019$ & $37.0 \pm 13.7$ \\
\hline
\end{tabular}

${ }^{1}$ Predicted using one-site ligand saturation modelling at a temperature of $20^{\circ} \mathrm{C}$

${ }^{2}$ Normalized to a salinity of 35 
PNNL-25899

\subsection{ORNL AF1-13-AO/DMSO}

The ORNL adsorbent AF1-13-AO/DMSO was one of the amidoxime-based adsorbent formulations that were investigated in the potassium bicarbonate re-usability study (Kuo et al., 2016). Illustrated in Figure 27 below is the time series data for the initial exposure of the braid in the flume. One site ligand saturation modelling of the AF8 time series data is given in Table 15.

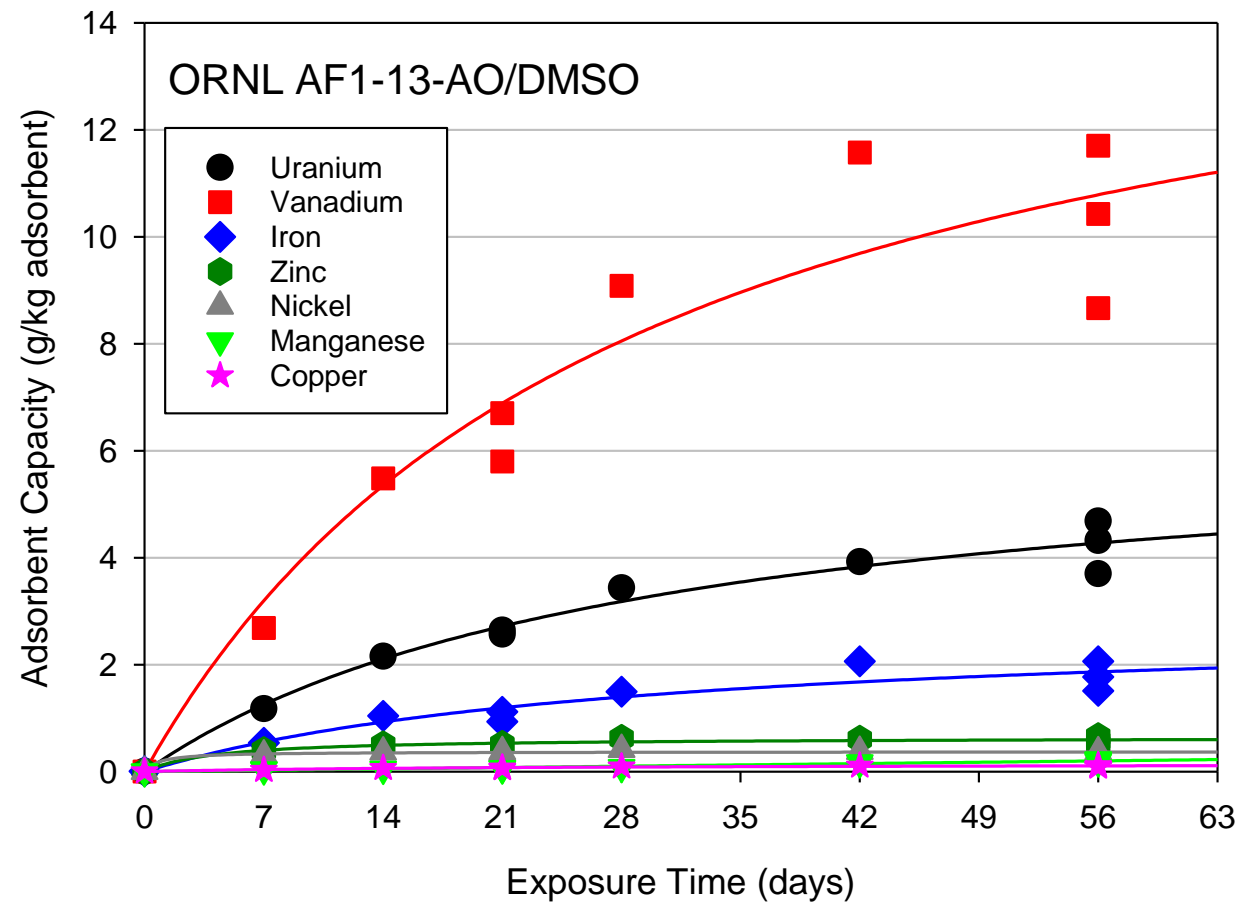

Figure 27. Time series measurements of adsorption capacity for the ORNL adsorbent AF1-13$\mathrm{AO} / \mathrm{DMSO}$ at $20^{\circ} \mathrm{C}$ using filtered Sequim Bay seawater. The best fit line drawn through the data points was determined using one-site ligand saturation modelling. All data were normalized to a salinity of 35 . 
PNNL-25899

Table 15. One-site ligand saturation modelling for the ORNL adsorbent AF1-13-AO/DMSO using recirculating flume exposures.

\begin{tabular}{lcccc}
\hline MSL ID & Element & $\begin{array}{c}\text { Saturation } \\
\text { Capacity } \mathbf{1 , 2} \\
\text { (g U/kg adsorbent) }\end{array}$ & $\begin{array}{c}\text { 56-day Adsorption } \\
\text { Capacity } \mathbf{1 , 2} \\
\text { (g U/kg adsorbent) }\end{array}$ & $\begin{array}{c}\text { Half Saturation } \\
\text { Time }^{\mathbf{1 , 2}} \\
\text { (days) }\end{array}$ \\
\hline $3540-33$ & $\mathrm{U}$ & $6.51 \pm 0.69$ & $4.27 \pm 0.15$ & $29.3 \pm 7.04$ \\
$3540-33$ & $\mathrm{~V}$ & $16.3 \pm 2.96$ & $10.8 \pm 1.95$ & $28.8 \pm 11.9$ \\
$3540-33$ & $\mathrm{Fe}$ & $2.81 \pm 0.56$ & $1.86 \pm 0.37$ & $28.5 \pm 12.9$ \\
$3540-33$ & $\mathrm{Zn}$ & $0.640 \pm 0.035$ & $0.59 \pm 0.033$ & $4.24 \pm 1.50$ \\
$3540-33$ & $\mathrm{Ni}$ & $0.372 \pm 0.018$ & $0.037 \pm 0.018$ & $0.86 \pm 0.93$ \\
$3540-33$ & $\mathrm{Mn}$ & $\mathrm{ND}$ & $\mathrm{ND}$ & $\mathrm{ND}$ \\
$3540-33$ & $\mathrm{Cu}$ & $0.145 \pm 0.018$ & $0.11 \pm 0.013$ & $20.0 \pm 6.84$ \\
\hline
\end{tabular}

${ }^{1}$ Predicted using one-site ligand saturation modelling at a temperature of $20^{\circ} \mathrm{C}$

${ }^{2}$ Normalized to a salinity of 35

\subsection{Discussion}

\subsection{Summary of and Comparison of Flow-Through Column and Recirculating Flume Time Series Exposure Tests}

Given in Tables 16 and 17 below is a summary of the adsorption capacities and halfsaturation times obtained for the flow-through column and recirculating flume exposures, respectively. There is nearly a doubling in adsorption capacity over the approximately 4 years of testing that this report covers (2012-2016), from the $38 \mathrm{H}$ adsorbent with a 56-day capacity of $3.30 \mathrm{~g} \mathrm{U} / \mathrm{kg}$ adsorbent to the more recent SB12-8 adsorbent with a capacity of $6.56 \mathrm{~g} \mathrm{U} / \mathrm{kg}$ adsorbent. In addition, the new LCW adsorbent has a half-saturation time that is considerably shorter than all of the previous adsorbents tested. This is a fairly remarkable achievement in such a short period of time.

Because multiple exposures were conducted with the AF series adsorbents in both flowthrough column and recirculating flume testing it provides a means to assess the performance of the exposure methods. There was excellent agreement between the 56-day adsorption capacity determined for the AF1 adsorbent with the recirculating flume exposure $(4.03 \pm 0.12 \mathrm{~g} \mathrm{U} / \mathrm{kg}$ adsorbent) and the flow-through column testing (3.91 $\pm 0.11 \mathrm{~g} \mathrm{U} / \mathrm{kg}$ adsorbent). The excellent agreement between the two exposure methods provides confidence that the exposure methods are producing reliable and accurate information. Moreover, it also suggests that the production of the adsorbent materials is highly reproducible, lending additional confidence of the robustness and homogeneity of the production technology. 
PNNL-25899

Table 16. Summary of flow-through column testing with amidoxime-based polymeric adsorbents at PNNL using filtered Sequim Bay seawater

\begin{tabular}{ccccc}
\hline & N & $\begin{array}{c}\text { Saturation } \\
\text { Capacity } \mathbf{1 , 2}\end{array}$ & $\begin{array}{c}\text { 56-day Adsorption } \\
\text { Capacity } \mathbf{1 , 2}\end{array}$ & $\begin{array}{c}\text { Half-saturation } \\
\text { Time }\end{array}$ \\
Adsorbent & (g U/kg adsorbent) & (g U/kg adsorbent) & (days) \\
\hline 38H & 4 & $4.29 \pm 0.24$ & $3.30 \pm 0.18$ & $16.9 \pm 2.8$ \\
AI8 & 1 & $5.17 \pm 0.18$ & $3.54 \pm 0.12$ & $25.8 \pm 2.1$ \\
AF1 & 5 & $5.56 \pm 0.15$ & $3.91 \pm 0.11$ & $24 \pm 1.5$ \\
AF1FR2 & 1 & $7.05 \pm 0.21$ & $5.00 \pm 0.15$ & $22.9 \pm 1.7$ \\
MAN1-AO/DMSO & 1 & $6.70 \pm 0.22$ & $5.04 \pm 0.16$ & $18.5 \pm 1.6$ \\
MAN8-AO/DMSO & 1 & $7.75 \pm 0.37$ & $5.09 \pm 0.24$ & $29.2 \pm 3.0$ \\
AN/MA/42kGY-a1 & 1 & $8.43 \pm 0.72$ & $5.13 \pm 0.44$ & $36 \pm 6.1$ \\
LCW-MSL-10 & 1 & $6.34 \pm 0.19$ & $5.28 \pm 0.16$ & $11.2 \pm 1.3$ \\
SB12-8 & 1 & $8.90 \pm 0.45$ & $6.56 \pm 0.33$ & $20.0 \pm 2.6$ \\
\hline
\end{tabular}

${ }^{1}$ Determined at a temperature of $20^{\circ} \mathrm{C}$

${ }^{2}$ Normalized to a salinity of 35

Table 17. Summary of recirculating flume testing with amidoxime-based polymeric adsorbents at PNNL using filtered Sequim Bay seawater

\begin{tabular}{ccccc}
\hline & N & $\begin{array}{c}\text { Saturation } \\
\text { Capacity } \mathbf{1 , 2} \\
\text { (g U/kg adsorbent) }\end{array}$ & $\begin{array}{c}\text { 56-day Adsorption } \\
\text { Capacity }^{\mathbf{1 , 2}} \\
\text { (g U/kg adsorbent) }\end{array}$ & $\begin{array}{c}\text { Half-saturation } \\
\text { Time }^{\mathbf{1 , 2}} \\
\text { (days) }\end{array}$ \\
\hline AI8 & 1 & $6.86 \pm 0.68$ & $4.13 \pm 0.41$ & $37 \pm 7.0$ \\
AF1 & 7 & $5.93 \pm 0.17$ & $4.03 \pm 0.12$ & $26.5 \pm 1.6$ \\
AF1-13- & & & & \\
AO/DMSO & 1 & $6.51 \pm 0.69$ & $4.27 \pm 0.15$ & $29.3 \pm 7.04$ \\
AF8 & 1 & $7.04 \pm 1.42$ & $3.62 \pm 0.73$ & $52.9 \pm 19.0$ \\
\hline
\end{tabular}

${ }^{1}$ Determined at a temperature of $20^{\circ} \mathrm{C}$

${ }^{2}$ Normalized to a salinity of 35

\subsection{Vanadium to Uranium Mass Ratio}

Vanadium is the element in highest mass abundance bound by the amidoxime ligand if one assumes that calcium and magnesium are primarily associated with the monomer on the adsorbent. Hence, changes in the relative binding of vanadium can be inferred to also affect the selectivity for the other elements. Based on this argument, the vanadium to uranium mass ratio can be used as a proxy measure of the selectivity of the ligands on the adsorbent for the adsorption of uranium. Increasing adsorbent selectivity is currently viewed as an optimization factor to improve adsorbent capacity and the $\mathrm{V} / \mathrm{U}$ ratio is being used as a measure of adsorbent selectivity. 
Given in Table 18 below is the vanadium to uranium mass ratio (V/U) for the amidoximebased adsorbents that were evaluated using flow-through column testing at PNNL. The amidoxime-based adsorbents in the AF series which were prepared by RIGP from acrylonitrile and itaconic acid on high surface area polyethylene fiber all had a fairly narrow V/U ratio, ranging between 3.6 and 4.2. The $38 \mathrm{H}$ adsorbent, also prepared by RIGP from acrylonitrile, but with a monocarboxylic monomer, had a lower V/U ratio of 2.2. The newest variations of the AF series adsorbents (MAN1-AO/DMSO and MAN8-AO/DMSO) also had similar V/U ratios, 4.2 \pm 0.4 and $3.6 \pm 0.3$, respectively, to the AF series adsorbents. The exception to this trend is the ORNL adsorbent AN/MA/42kGY-a1, which had a considerably lower V/U ratio of 1.9, a much lower value then the other AF series adsorbents. The UT/ORNL amidoxime-based adsorbent SB12-8, which was prepared by ATRP, had a V/U ratio of 2.2, suggesting an improved selectivity over the ORNL AF series adsorbents. The amidoxime-based adsorbent with the lowest V/U ratio is the LCW adsorbent LCW-MSL-10, with a V/U ratio of 1.2. This adsorbent was not prepared by RIGP, but rather conversion of the naturally present nitrile groups on the acrylic fiber by chemical conversion.

Table 18. Vanadium to uranium mass ratio for several amidoxime-based adsorbents that were exposed to natural seawater in the flow-through column testing at PNNL.

\begin{tabular}{cc} 
Adsorbent & V/U Mass Ratio ${ }^{1}$ \\
\hline $38 H$ & 2.2 \\
AI8 & 4.6 \\
AF1 & $3.6 \pm 0.5$ \\
AF1FR2 & $3.9 \pm 0.3$ \\
MAN1-AO/DMSO & $4.2 \pm 0.4$ \\
MAN8-AO/DMSO & $3.6 \pm 0.3$ \\
AN/MA/42kGY-a1 & 1.9 \\
LCW-MSL-10 & 1.2 \\
SB12-8 & 2.2 \\
\hline
\end{tabular}

${ }^{1}$ The $\mathrm{V} / \mathrm{U}$ mass ratio is based on replicate determinations of the 56-day exposure time point. Where more than two determinations were made the mean and standard deviation is reported.

\subsection{Summary and Conclusions}

Repeated time series measurements of a common formulation of amidoxime-based adsorbent, the ORNL AF series, by both flow-through column and recirculating flume exposures produced 56-day adsorption capacities that agreed very well. This excellent agreement generates confidence that the testing procedures are accurate and reliable and moreover, that the technology to produce the adsorbents is highly reproducible. 
Over the four year period (2012-2016) that marine testing of amidoxime-based polymeric adsorbents was conducted at PNNL's Marine Science Laboratory, there has been a steady progression of improvement in the 56-day adsorbent capacity from 3.30 to $6.56 \mathrm{~g} \mathrm{U} / \mathrm{kg}$ adsorbent. This is a significant advancement in the amidoxime-based adsorbent technology, particularly when compared to the several decades of work conducted by the Japanese scientists beginning in the 1980's (Kim et al., 2013). The best adsorbent capacity reported by the Japanese scientists was $3.2 \mathrm{~g} \mathrm{U} / \mathrm{kg}$ adsorbent for a 180 day deployment at temperatures between 15 and $25{ }^{\circ} \mathrm{C}$ (Kim et al., 2013) The majority of the capacities the Japanese scientists reported was less than $2 \mathrm{~g} \mathrm{U} / \mathrm{kg}$ adsorbent (Kim et al., 2013).

\subsection{References}

Brown, S. S. Chatterjee, M. Li, Y. Yue, C. Tsouris, C. J. Janke, T. Saito, and S. Dai (2016a). Uranium Adsorbent Fibers Prepared by Atom-Transfer Radical Polymerization from Chlorinated Polypropylene and Polyethylene Trunk Fibers. Industrial \& Engineering Chemistry Research, 55: 4130-4138. DOI: 10.1021/acs.iecr.5b03667.

Brown S., Y. Yue, L-J. Kuo, N. Mehio, M. Li, G. Gill, C. Tsouris, R. T. Mayes, T. Saito, and S. Dai (2016b). Uranium Adsorbent Fibers Prepared by Atom-Transfer Radical Polymerization (ATRP) from Poly(vinyl chloride)-co-chlorinated Poly(vinyl chloride) (PVC-co-CPVC) Fiber. Industrial \& Engineering Chemistry Research, 55: 4139-4148. DOI: 10.1021/acs.iecr.5b03355.

Das, Sadananda, Y. Oyola, Richard T. Mayes, Christopher J. Janke, Li-Jung Kuo, G. A. Gill, Jordana R. Wood, and Sheng Dai (2016). Extracting Uranium from Seawater: Promising AI Series Adsorbents. Industrial \& Engineering Chemistry Research, 55: 4103-4109. DOI: 10.1021/acs.iecr.5b03135.

Das, Sadananda; Y. Oyola, Richard T. Mayes, Christopher J. Janke, Li-Jung Kuo, G. A. Gill, Jordana R. Wood, and Sheng Dai (2016). Extracting Uranium from Seawater: Promising AF Series Adsorbents. Industrial \& Engineering Chemistry Research, 55: 4110-4117. DOI: 10.1021/acs.iecr.5b03136.

DOE (2010). Nuclear Energy Research and Development Roadmap: Report to Congress; U.S. Department of Energy: Washington, D. C., 2010. Report available at: http://www.energy.gov/ne/downloads/nuclear-energy-research-and-development-roadmap

Gill, Gary A., Li-Jung Kuo, Jordana Wood and Chris Janke (2014). Complete Laboratory Evaluation and Issue a Report on the Impact of Temperature on Uranium Adsorption. Prepared for: U. S. Department of Energy, Office of Nuclear Energy, Fuel Cycle Research and Development Program, Fuel Resources Program. Pacific Northwest National Laboratory, Sequim, WA 98382. PNNL Information Release Number: PNNL-23634. Report available at: http://www.pnl.gov/publications/. 
Gill, Gary A., Li-Jung Kuo, Jonathan Strivens, Jordana Wood, Nicholas Schlafer Costas Tsouris, Austin Ladshaw and Sotira Yiacoumi (2015). Investigations into the Effect of Current Velocity on Amidoxime-Based Polymeric Uranium Adsorbent Performance. Milestone Report M2FT-16PN030201042 submitted to the U. S. DOE Fuel Resources Program. Submittal date 12-1-2015. PNNL Report number PNNL-24996. This report is available from the Pacific Northwest National Laboratory Publications Web page: http://www.pnl.gov/publications/.

Gill, G. L.-J. Kuo, J. Strivens, J. Wood, N. Schlafer, E. D’Alessandro (2016). Uranium from seawater marine testing program at the University of Miami's Broad Key Island Research Station. Milestone Report M3FT-16PN030201045 submitted to the U. S. DOE Fuel Resources Program. Submittal date 9-1-2016. PNNL Report number PNNL-25734. This report is available from the Pacific Northwest National Laboratory Publications Web page: http://www.pnl.gov/publications/.

Gill, Gary A., Li-Jung Kuo, Chris J. Janke, Jordana R. Wood, Richard T. Mayes, Costas Tsouris, Yatsandra Oyola, Jonathan E. Strivens, Michael Cobb , George Bonheyo , Robert Jeters, Jiyeon Park, Tarang Khangaonkar, R. Shane Addleman, Wilaiwan Chouyyok, Marvin Warner, Sonja Peterson, David G. Abrecht, Sadananda Das, Ken Buesseler, Crystal Breier, Evan D'Alessandro, Horng-Bin Pan and Chien Wai (2016). The Uranium from Seawater Program at PNNL: Overview of Marine Testing, Adsorbent Characterization, Adsorbent Durability, Adsorbent Toxicity, and Deployment Studies. Industrial \& Engineering Chemistry Research. 55: 4264-4277. DOI: 10.1021/acs.iecr.5b03649.

Kim, J.; Oyola, Y.; Tsouris, C.; Hexel, C. R.; Mayes, R. T.; Janke, C. J.; Dai, S.(2013). Characterization of uranium uptake kinetics from seawater in batch and flow-through experiments. Industrial \& Engineering Chemistry Research, 52: 9433-9440.

Kim, J.; Tsouris, C.; Oyola, Y.; Janke, C. J.; Mayes, R. T.; Dai, S.; Gill, G.; Kuo, L. J.; Wood, J.; Choe, K. Y.; Schneider, E.; Lindner, H. (2014). Uptake of uranium from seawater amidoxime-based polymeric adsorbent: Field experiments modeling and updated economic assessment. Industrial \& Engineering Chemistry Research, 53: 6076-6083.

Kim, J.; Tsouris, C.; Mayes, R. T.; Oyola, Y.; Saito, T.; Janke, C. J.; Dai, S.; Schneider, E.; and Sachde, D. (2013). Recovery of Uranium from Seawater: A Review of Current Status and Future Research Needs, Separation Science and Technology, 48:3, 367-387, DOI: 10.1080/01496395.2012.712599.

Kuo, Li-Jung, Gary A Gill, Jonathan Strivens, Jordana Wood, Nicholas Schlafer, Chien M. Wai, and Horng-Bin Pan (2016). Investigations Into the Reusability of Amidoxime-Based Polymeric Uranium Adsorbents. Milestone Report M3FT-16PN030201047 submitted to the U. S. DOE Fuel Resources Program. Submittal date 9-30-2016. PNNL Report number PNNL-25874. This report is available from the Pacific Northwest National Laboratory Publications Web page: http://www.pnl.gov/publications/.

Kuo, Li-Jung, Christopher Janke, Jordana R. Wood, Jonathan E. Strivens, and Gary A. Gill (2016). Characterization and Testing of Amidoxime-Based Adsorbent Materials to Extract Uranium 
PNNL-25899

from Natural Seawater. Industrial \& Engineering Chemistry Research, 55 (15), 4285-4293; DOI: $10.1021 /$ acs.iecr.5b03267.

Oyola, Y., C.J. Janke and S. Dai (2016). Synthesis, development, and testing of high-surface-area polymer-based adsorbents for the selective recovery of uranium from seawater. . Industrial \& Engineering Chemistry Research, 55 (15), 4149-4160; DOI: 10.1021/acs.iecr.5b03981.

Park, Jiyeon, Gary A. Gill, Jonathan E. Strivens, Li-Jung Kuo, Robert T. Jeters, Andrew Avila, Jordana R. Wood, Nicholas J. Schlafer, Christopher J. Janke, Erin A. Miller, Matthew Thomas, R. Shane Addleman and George T. Bonheyo (2016). Effect of biofouling on the performance of amidoxime-based polymeric uranium adsorbents. Industrial \& Engineering Chemistry Research, 55, 4328-4338, DOI: 10.1021/acs.iecr.5b03457.

Wood, Jordana, R., Gary A. Gill, Li-Jung Kuo, Jonathan E. Strivens and Key-Young Choe (2016). Comparison of Analytical Methods for the Determination of Uranium in Seawater using Inductively Coupled Plasma Mass Spectrometry. Industrial \& Engineering Chemistry Research, 55: 4344-4350, DOI: 10.1021/acs.iecr.5b03680. 


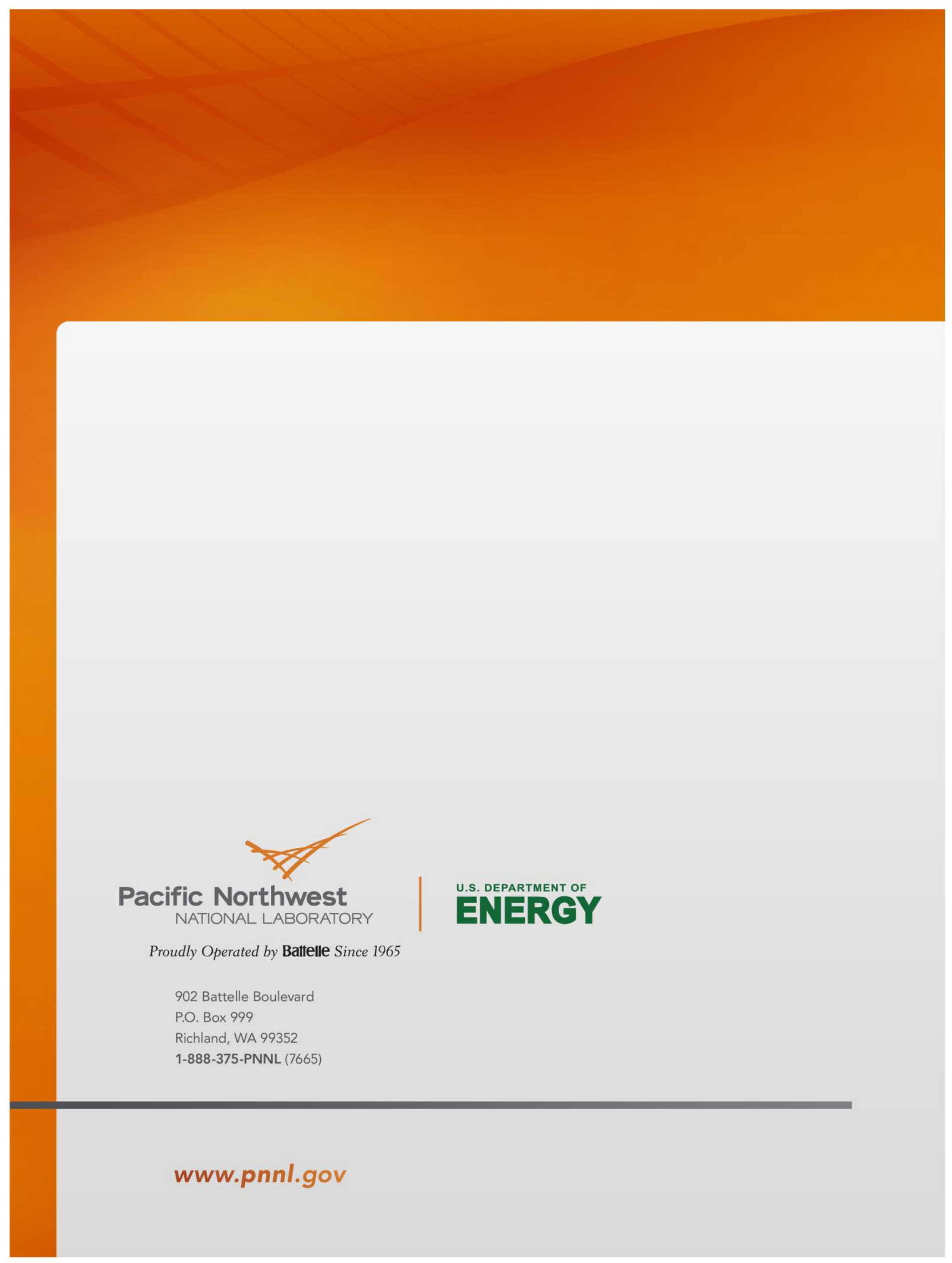

